Digital Comprehensive Summaries of Uppsala Dissertations from the Faculty of Medicine 534

\title{
Metabolic Aspects in the Polycystic Ovary Syndrome
}

ÅSA MARIA LINDHOLM 
Dissertation presented at Uppsala University to be publicly examined in Konferenscentrum, Sunderby sjukhus, Luleå, Friday, April 23, 2010 at 12:00 for the degree of Doctor of Philosophy (Faculty of Medicine). The examination will be conducted in Swedish.

\author{
Abstract \\ Lindholm, Å M. 2010. Metabolic Aspects in the Polycystic Ovary Syndrome. Acta \\ Universitatis Upsaliensis. Digital Comprehensive Summaries of Uppsala Dissertations from \\ the Faculty of Medicine 534. 65 pp. Uppsala. ISBN 978-91-554-7746-2.
}

Polycystic ovary syndrome (PCOS) is one of the most common endocrine disorders among women of childbearing age and is associated with a number of metabolic disturbances. It has been hypothesised these women carry an increased risk of developing cardiovascular diseases (CVD) with advancing age.

The first aim of this thesis was to establish the prevalence of PCOS-related symptoms in Northern Sweden. The Northern part of the WHO MONICA project was used for this purpose. Based on self-reported menstrual disturbances and hirsutism together with biochemical analyses of free androgen index, the estimated prevalence of PCOS in Northern Sweden was 4.8\%, which corresponded with previous prevalence studies.

Disturbances in the fibrinolytic system are predictors of future cardiovascular events and measurements of plasminogen activator inhibitor 1 (PAI-1) activity and tissue plasminogen activator (tPA) mass concentration may be used to assess fibrinolytic activity in women with PCOS. From the findings, over-weight women with PCOS had impaired fibrinolysis, especially if they displayed objective biochemical markers of hyperandrogenism. Conversely, lean women with PCOS, displayed no signs of disturbed fibrinolysis.

The adipose tissue is an active endocrine organ that produces and releases hormones, proand anti-inflammatory cytokines, and chemoattractant cytokines. Proinflammatory molecules produced by adipose tissue can be active participants in the development of insulin resistance and the increased risk of cardiovascular disease associated with obesity. The findings suggested being overweight, rather than the PCOS diagnosis per se, was the main explanatory variable for elevated adipose tissue inflammation in PCOS patients.

Weight reduction is the primary target for intervention in overweight and obese women with PCOS. When this thesis was planned, no placebo-controlled trials on anti-obesity drugs in women with PCOS had been conducted. Sibutramine in combination with lifestyle intervention resulted in significant weight reduction in overweight women with PCOS. In addition to the weight loss, sibutramine appeared to have a beneficial effect on metabolic and cardiovascular risk factors.

Keywords: PCOS, prevalence, fibrinolysis, inflammatory markers, over weight

Asa Maria Lindholm, Department of Women's and Children's Health, Akademiska sjukhuset, Uppsala University, SE-75185 Uppsala, Sweden

(C) Åsa Maria Lindholm 2010

ISSN 1651-6206

ISBN 978-91-554-7746-2

urn:nbn:se:uu:diva-120235 (http://urn.kb.se/resolve?urn=urn:nbn:se:uu:diva-120235) 


\section{List of Papers}

This thesis is based on the following papers, which are referred to in the text by their Roman numerals.

I Lindholm A, Andersson L, Eliasson M, Bixo M, Sundstrom-Poromaa I. Prevalence of symptoms associated with polycystic ovary syndrome. Int J Gynaecol Obstet 2008; 102(1):39-43.

II Lindholm A, Bixo M, Eliasson M, Hudecova M, Arnadottir J, Holte, J, Sundström Poromaa I. Tissue plasminogen activator and plasminogen activator inhibitor 1 in overweight and lean patients with polycystic ovary syndrome. Submitted.

III Lindholm A, Blomquist C, Bixo M, Dahlbom I, Hansson T, Sundström Poromaa I, Burén J. Adipose tissue inflammation in polycystic ovary syndrome (PCOS). Submitted

IV Lindholm A, Bixo M, Bjorn I, Wolner-Hanssen P, Eliasson M, Larsson A, Johnson O, Sundström-Poromaa I. Effect of sibutramine on weight reduction in women with polycystic ovary syndrome: a randomized, double-blind, placebo-controlled trial. Fertil Steril 2008; 89:1221-1228

Reprints were made with permission from the respective publishers.

Cover illustration made by Liselott Andersson. 



\section{Contents}

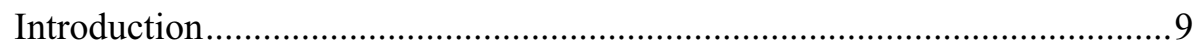

Polycystic ovaries and the polycystic ovary syndrome ...............................

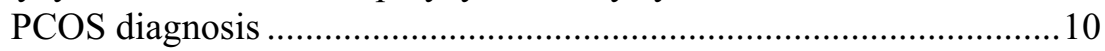

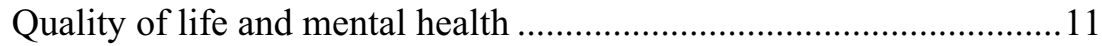

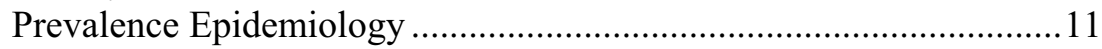

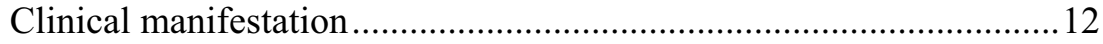

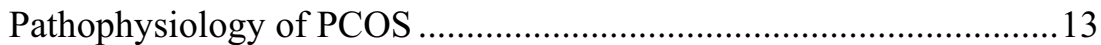

Metabolic consequences of PCOS ....................................................... 14

Cardiovascular consequences of PCOS ...............................................16

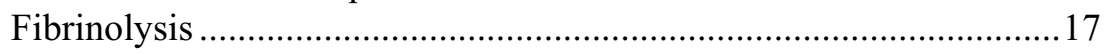

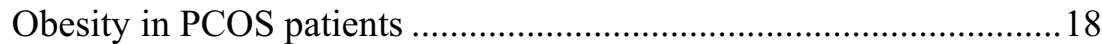

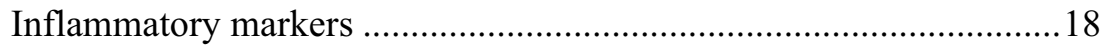

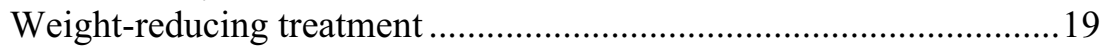

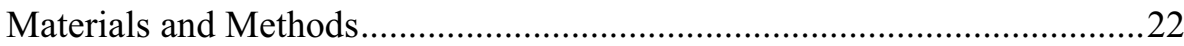

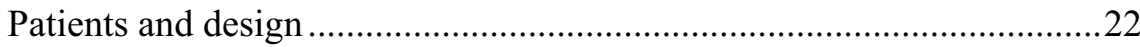

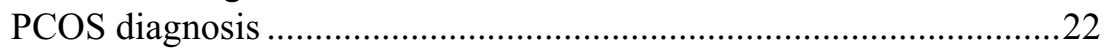

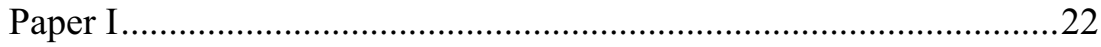

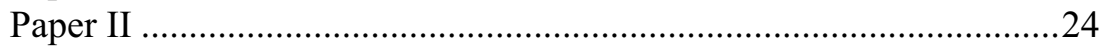

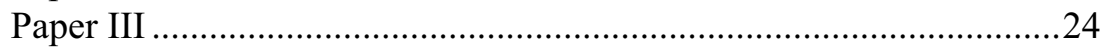

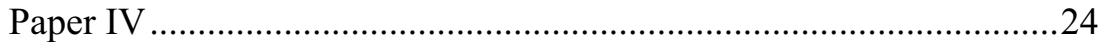

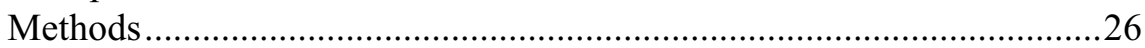

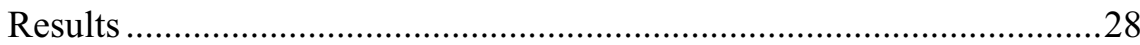

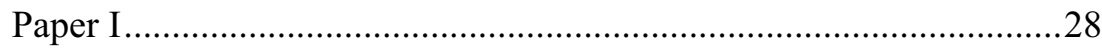

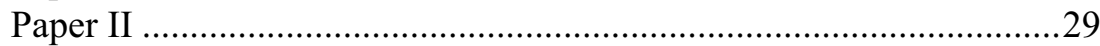

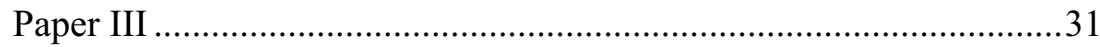

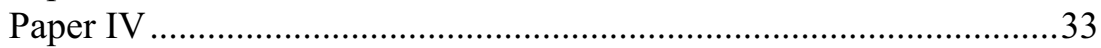

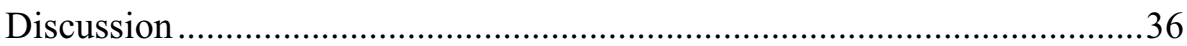

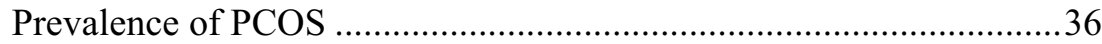

Fibrinolytic activity in women with PCOS............................................38

Inflammatory markers in adipose tissue of PCOS women ..................39

Weight reduction treatment in women with PCOS ..............................41

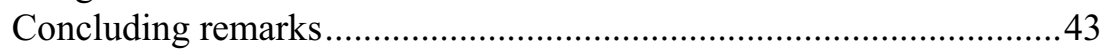

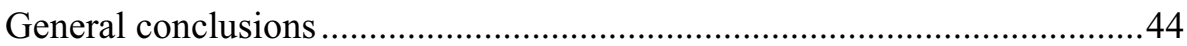

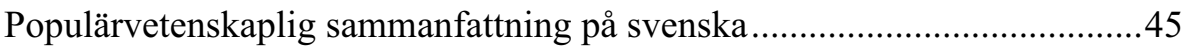

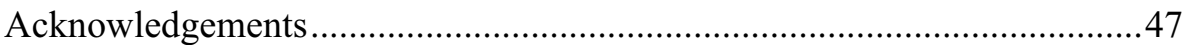

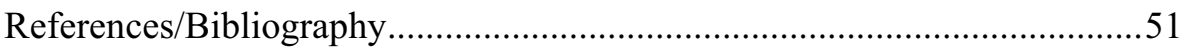





\section{Abbreviations}

$\begin{array}{ll}\text { AE-PCOS } & \text { The Androgen Excess and PCOS Society } \\ \text { ASRM } & \text { American Society for Reproductive Medicine } \\ \text { BMI } & \text { Body mass index } \\ \text { BP } & \text { Blood pressure } \\ \text { CCL2 } & \text { Chemokine (C-C motif) ligand 2 (also MCP-1) } \\ \text { CCR2 } & \text { Chemokine receptor 2 } \\ \text { CD14 } & \text { Cluster of differentiation (cell surface mole- } \\ & \text { cules present on white blood cells) 14 } \\ \text { CD163 } & \text { Cluster of differentiation (cell surface mole- } \\ & \text { cules present on white blood cells)163 } \\ \text { cDNA } & \text { Complementary DNA } \\ \text { COC } & \text { Combined oral contraceptives } \\ \text { CRP } & \text { C-reactive protein } \\ \text { CVD } & \text { Cardiovascular disease } \\ \text { DHEAS } & \text { Dehydroepiandrosterone sulfate } \\ \text { ESHRE } & \text { European Society for Human Reproduction \& } \\ & \text { Embryology } \\ \text { EMA } & \text { European Medicines Agency } \\ \text { FAI } & \text { Free androgen index } \\ \text { FDP } & \text { Fibrin degradation products } \\ \text { FP } & \text { Fasting plasma } \\ \text { FSH } & \text { Follicle stimulating hormone } \\ \text { HDL } & \text { High-density lipoprotein } \\ \text { hs-CRP } & \text { High sensitive c-reactive protein } \\ \text { HOMA-IR } & \text { Homeostasis model assessment of insulin resis- } \\ & \text { tance } \\ \text { IDF } & \text { International Diabetes Federation } \\ \text { IFG } & \text { Insulin-like growth factor } \\ \text { IGT } & \text { Impaired glucose tolerance } \\ \text { IL-18 } & \text { Interleukin-18 } \\ \text { IR } & \text { Insulin resistance } \\ \text { IVF } & \text { In vitro fertilization } \\ \text { LH } & \text { Luteinizing hormone } \\ \text { LDL } & \text { Low-density lipoprotein } \\ \text { MBS } & \text { Metabolic Syndrome } \\ & \end{array}$


MCP-1

MIF

MONICA

mRNA

NCEP

$\mathrm{NIH}$

OGTT

PAI-1

PCO

PCOS

PCR

PPIA

QoL

$\mathrm{R}^{2}$

RNA

RPLP0

SCOUT

SHBG

SPSS

$\mathrm{T}$

TG

TNF- $\alpha$

tPA

TSH

WHO
Monocyte chemoattractant protein-1 (also CCL2)

Macrophage migration inhibitory factor

Multinational MONItoring of trends and determinants in CArdiovascular disease Messenger-RNA

National Cholesterol Education Program

The US National Institute of Health

Oral glucose tolerance test

Plasminogen activator inhibitor 1

Polycystic ovary

Polycystic ovary syndrome

Polymerase chain reaction

Peptidylprolyl isomerase A

Quality of Life

Coefficient of determination

Ribonucleic acid

Ribosomal protein, large, $\mathrm{P} 0$

Sibutramine Cardiovascular OUTcomes trial

Sexual hormone binding globulin

Statistical Package for the Social Sciences

Testosterone

Triglycerides

Tumor necrosis factor- $\alpha$

Tissue plasminogen activator

Thyroid stimulating hormone

World Health Organization 


\section{Introduction}

\section{Polycystic ovaries and the polycystic ovary syndrome}

Polycystic ovary syndrome (PCOS), one of the most common endocrine disorders in women of childbearing age $[1,2]$, is a heterogeneous clinical condition characterized by hyperandrogenism and signs of chronic oligo/anovulation. Recent changes in diagnostic criteria may have further increased the heterogeneity of the patient population.

Polycystic ovaries (PCO) were first described by Stein and Leventhal in 1935 , but were not included in the diagnostic criteria for polycystic ovary syndrome (PCOS) until 2003. Polycystic ovaries are characterized by stroma hyperplasia, increased numbers of follicles less than $8 \mathrm{~mm}$ and, often but not always enlarged ovaries [3]. Currently, polycystic ovaries are diagnosed by transvaginal ultrasound and defined as the presence of 12 or more follicles, measuring 2-9 $\mathrm{mm}$ in diameter, in each ovary and/or increased ovarian volume (>10 ml) [2]. However, the typical ultrasound feature is only one criterion for the whole syndrome, as polycystic ovaries also can appear in otherwise healthy women [4]. Hence, for PCOS diagnosis a further criterion has to be present.

Most women diagnosed with PCOS in the gynecologic setting present with symptoms of oligomenorrhea or amenorrhea and seek medical care primarily because they fear their menstrual disturbance may impair future or present fertility. Other reasons for seeking medical care include hirsutism, manifest infertility, and anovulatory menometrorrhagia. Most women are diagnosed after the age of 18-20 years, as hyperandrogenism and menstrual disturbances are considered common symptoms during normal adolescence [5]. However, because of the heterogeneity of the syndrome, women with PCOS may be encountered in various clinical settings such as the dermatological-, endocrinological-, and surgical departments.

A number of health risks are associated with PCOS, among which the most common are obesity, insulin resistance, type 2 diabetes [6-8], and changes in lipid profile [9-11]. Possible health risks include cardiovascular disease (CVD) [12] and associated risk factors [13-15]. However, whether all women with PCOS carry a similar increased risk for type 2 diabetes and cardiovascular disease remains unknown. 


\section{PCOS diagnosis}

Different diagnostic criteria have been used for the PCOS diagnosis. In 1990, a conference sponsored by the U.S. National Institute of Health (NIH) put forward recommendations concerning diagnostic criteria for PCOS, which included clinical or biochemical hyperandrogenism together with chronic anovulation, provided other disorders such as late onset congenital adrenal hyperplasia, androgen secreting tumors, and Cushing's syndrome had been excluded [16]. The NIH criteria are sometimes referred to as "classical PCOS".

Since 1990, it has become apparent, especially in the infertility setting many women present with ovarian dysfunction and polycystic ovaries on ultrasound but without clinical evidence of androgen excess. In 2003, a consensus group, with representatives from the European Society for Human Reproduction \& Embryology (ESHRE) and the American Society for Reproductive Medicine (ASRM), modified the criteria to include transvaginal ultrasound evaluation of the ovaries. The revised ESHRE/ASRM criteria (also referred to as the Rotterdam criteria) are the ones primarily used in this thesis. The criteria stipulate two of the three following features should be present: signs of chronic anovulation; clinical or biochemical hyperandrogenism; and typical ultrasonographic appearance of the ovaries, provided other disorders with similar clinical presentation are excluded [17]. With the addition of the ESHRE/ASRM criteria, two new PCOS phenotypes emerged: patients with oligomenorrhea and polycystic ovaries (sometimes referred to as "PCOS light"); and, patients with hyperandrogenism and polycystic ovaries.

In 2006, a third definition of the diagnosis was suggested by the Androgen Excess and PCOS Society (AE-PCOS), formerly known as the Androgen Excess Society, emphasizing the hyperandrogenic features of the syndrome. The AE-PCOS proposed a PCOS diagnosis that includes the criteria: clinical and/or biochemical hyperandrogenism as obligate criteria, and/or, ovarian dysfunction expressed as oligo/anovulation, and/or polycystic ovaries, and exclusion of other androgenic disorders [18].

Table 1. Diagnostic criteria for PCOS.

\begin{tabular}{cccc}
\hline & NIH & ESHRE/ASRM & AE-PCOS \\
\hline Hyperandrogenism & + & $+/-$ & + \\
Olig/Anovulation & + & $+/-$ & $+/-$ \\
PCO ultrasound & - & $+/-$ & $+/-$ \\
\hline
\end{tabular}

Depending on which criteria are used, the prevalence of PCOS differs in the same population. For example, the diagnostic criteria according to AE-PCOS exclude women without hyperandrogenic symptoms, thus, entailing a lower 
prevalence than the ESHRE/ASRM criteria. Conversely, the AE-PCOS criteria will result in a slightly higher prevalence than the NIH criteria, in which oligo/anovulation is only assessed by reports on menstrual disturbances and not by ultrasound features (Table 1).

In addition to the plausible differences in prevalence rates, it has been suggested that the different criteria may be associated with different metabolic disturbances [19]. For instance, the ESHRE/ASRM criteria will, in addition to women with classical PCOS (i.e. PCOS diagnosed according to NIH criteria), include the PCOS phenotype with oligomenorrhea and polycystic ovaries. This PCOS phenotype is associated with a slightly lower risk for obesity, insulin resistance, hypertension and (hypothetically), fewer cardiovascular complications [20-22].

\section{Quality of life and mental health}

PCOS is not only associated with metabolic consequences and reduced fertility but may also influence the quality of life and mental health of affected women. Although most research in the field of mental health and PCOS is devoted to the psychological consequences of infertility [23], other symptom of PCOS may, individually or in concert, negatively affect quality of life (QoL) and mental health of women with PCOS [24].

Independent of obesity/overweight, clinical depression and depressive symptoms appear to be more common among PCOS women than in weight matched controls [25-27]. Likewise, anxiety symptoms including phobic symptoms appear to be more common among PCOS patients [28]. Without adjusting for the confounding effect of overweight, women with PCOS have higher lifetime incidence of social phobia and eating disorders and more often report previous suicide attempts than healthy controls [29]. Current and lifetime use of antidepressants and anxiolytic drugs also appear to be more common in the PCOS group [29].

Needless to say, clinical depression is important to identify in PCOS patients, not only because of the specific disease burden associated with major depression, but also because reduced motivation is a common feature of depression. Reduced motivation, in turn, may negatively impact the success of weight-reducing therapies.

\section{Prevalence Epidemiology}

The estimated prevalence for PCOS is approximately $5-10 \%$ among fertile women, but a precise determination has not been obtained [30-32]. When this thesis was planned, only two population-based studies had been conducted and neither included the ultrasound criterion. These studies are criticized, as women on combined oral contraceptives (COC) were often excluded. It is thought that the exclusion of COC users will yield an underes- 
timation of the true prevalence of PCOS, as the syndrome per se may predispose patients to the use of hormonal therapy.

One of the prevalence studies with a population-based effort is a Greek study [30] from the island of Lesbos, which included 192 women (age 17 45 years) invited to a free medical examination through public advertisements in newspapers and on television. In this Greek island population, the prevalence of PCOS was $6.8 \%$ [30]. PCOS was diagnosed according to the NIH criteria and the definition of hyperandrogenism was a FerrimanGallwey score $\geq 6$ or free plasma testosterone higher than the 95th percentile: other possible causes for the symptom profile were excluded.

In addition, a Finnish population-based study on self-reported PCOS symptoms [33] diagnosed PCOS according to NIH, and assessed hyperandrogenism through self-report. Women on COC were excluded from the study. Overall, the prevalence of PCOS in the Finnish sample was estimated to be $3.4 \%$, which may be an underestimation as there was no assessment of biochemical hyperandrogenism in addition to self-reported hirsutism.

Two other prevalence studies are also available, including a Spanish study of 154 female blood donors (18-45 years) [32]. PCOS was diagnosed according to NIH and hyperandrogenism was defined as Ferriman-Gallwey score $\geq 8$ and/or free plasma testosterone and/or dehydroepiandrosterone sulfate (DHEAS) and/or free androgen index (FAI) higher than the 95th percentile. The prevalence of PCOS in Spain is estimated as 6.5\% [32]. In a U.S. study [31] of 400 fertile women (ages 18-45) attending a preemployment physical examination at the University of Alabama, $56 \%$ of the women included were overweight or obese and 140 were COC users. PCOS was diagnosed according to NIH and hyperandrogenism defined as Ferriman-Gallwey score $\geq 6$ and/or total testosterone and/or androstendione and/or DHEAS level above the 95th percentile: related syndromes were excluded. The total prevalence of PCOS in this population was $6.6 \%$, but prevalence rates differed between ethnic groups $(8.0 \%$ of black women and $4.8 \%$ of white women).

According to NIH criteria, the prevalence rates of PCOS may differ between ethnic groups, with white American women and Scandinavian women displaying the lowest prevalence of PCOS. Due to the possible underestimation of PCOS in Scandinavian women, this work was an attempt to determine the PCOS prevalence rate in Northern Sweden.

\section{Clinical manifestation}

\section{Hirsutism/hyperandrogenism}

In clinical studies on PCOS, hirsutism is usually scored by the FerrimanGallway score. However, besides inter-rater variability in scorings, hirsutism is, in reality, difficult to assess, as many women have already treated their 
symptoms prior to clinical evaluation. Biochemical hyperandrogenism is readily assessed by calculating the free androgen index (FAI) with the formula [testosterone/sex hormone binding globulin (SHBG)] x 100 [34]. Approximately $80 \%$ of testosterone is bound to SHBG, $19 \%$ to albumin, and only $1 \%$ of testosterone is free and biologically available and active in women. For this reason, total testosterone is insufficient for evaluation of androgens in women [35]. Free testosterone is possible to measure with a direct immunoassay method but the assay only retrieves $20-60 \%$ of the levels compared with the equilibrium dialysis method, the gold standard free testosterone analysis [36]. Free androgen index is affected by circulating levels of SHBG and testosterone [37], but correlates relatively well with the more costly equilibrium dialysis method. In this thesis, a cut-off for free androgen index $>5$ was used, based on recommendations from the Gynecologic Endocrinology Section of the Swedish Society of Obstetricians and Gynecologists [38]. This cut-off depends on the reference intervals for testosterone (0.5-3 nmol/1) and SHBG (35-150 nmol/1) and may not be applicable in settings where other reference intervals are used. Other androgens often used for diagnostic purposes include DHEAS and androstendione [17, $18]$.

\section{Anovulation/menstrual disturbances}

The other diagnostic criterion - oligomenorrhea or amenorrhea - as signs of anovulation is usually the reason a patient visits the gynecologist. Although there is no clear-cut recommendation to what should be considered as oligomenorrhea, for research purposes, a definition of less than eight menstruations a year, or menstrual cycles longer than 35 days, is usually applied [39]. A definition of cycle length of less than 21 days or greater than a 4-day variation between cycles is sometimes proposed; however, the rationale for this definition is unclear $[40,41]$.

\section{Pathophysiology of PCOS}

The genetic predisposition for PCOS has been evaluated, and a familiar clustering is indicated $[42,43]$ with higher androgen levels, increased prevalence of insulin resistance [43] and more often CVD in first-degree relatives [4446]. The genetic contribution for symptom development in individual subjects is difficult to ascertain although $35 \%$ of mothers and $40 \%$ of sisters of women with PCOS also display characteristics of the syndrome [42]. There is no established male phenotype, but male relatives to women with PCOS have higher rates of obesity and insulin resistance than male controls [47, 48].

Hyperandrogenism in women with PCOS is considered a consequence of abdominal obesity [49], insulin resistance and/or resulting hyperinsulinemia, but may also be a contributing factor to the insulin resistance and abdominal 
adiposity displayed by patients [49]. Long-term administration of testosterone in female-to-male transsexuals induces abdominal adiposity and insulin resistance [50], and androgen excess during fetal life and infancy is associated with increased risk of developing abdominal adiposity later in life [5153]. Thus, chronic androgen excess in PCOS patients could favor insulin resistance by determining a predominantly abdominal distribution of body fat (Figure 1).

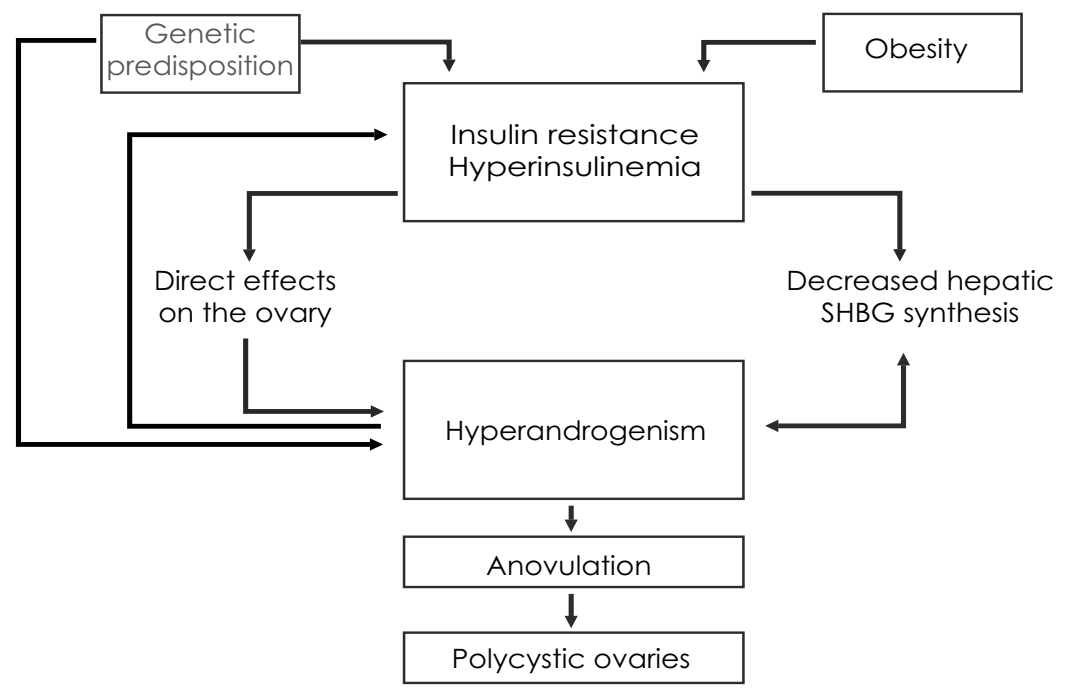

Figure 1. Simplified theoretical model for the pathophysiology underlying PCOS.

The interplay between hyperandrogenism and insulin resistance has led to the suggestion that PCOS and its metabolic co-morbidities could be explained by the existence of a 'vicious circle', whereby, a chronic androgen excess of ovarian and/or adrenal origin results in abdominal adiposity in affected women [49]. Conversely, abdominal adiposity, through insulin resistance and hyperinsulinism, favors further hyperandrogenism through different pathways including the ovaries, hepatic SHBG synthesis and, possibly the pituitary and adrenals [54] (Figure 1).

\section{Metabolic consequences of PCOS}

PCOS is associated with metabolic disturbances such as insulin resistance and hyperinsulinism, type 2 diabetes, dyslipidemia and, possibly cardiovascular disease [6]. Increased insulin resistance appears a crucial mechanism behind this association and is a common feature in PCOS and the metabolic syndrome (MBS). PCOS could be regarded as a variant of the metabolic syndrome that, for obvious reasons, only affects women. However, the correlation between PCOS and MBS is difficult to assess, as MBS has more 
than one definition and numerous diagnostic criteria are suggested [55] (Table 2). In this thesis, the term metabolic disturbance was used, as individual criteria for MBS are associated with health risks.

Women with PCOS have multiple risk factors for type 2 diabetes including obesity, a family history of type 2 diabetes and, abnormalities in insulin action $[12,49,56]$. Studies over the past two decades indicated that insulin resistance has been convincingly identified as an integral pathogenic feature of PCOS, particularly in obese individuals [57-59]. Furthermore, insulin resistance in PCOS patients is closely associated with abdominal obesity and hyperandrogenism [60-63], and PCOS patients are generally insulin resistant at lower BMI levels $\left(27-28 \mathrm{~kg} / \mathrm{m}^{2}\right)$ than healthy controls $[9,58,64,65]$.

However, heterogeneity within the PCOS sample is reflected by more conflicting results regarding insulin resistance in lean PCOS patients with some studies [61, 66-69] indicating increased insulin resistance and other [70-73] indicating no difference between lean PCOS patients and weightmatched controls. In some studies $[74,75]$ PCOS patients without hyperandrogenic features are not insulin resistant. 
Table 2. Different diagnostic criteria of the metabolic syndrome.

\begin{tabular}{|c|c|c|c|}
\hline WHO & NCEP & IDF & ESHRE/ASRM \\
\hline $\begin{array}{l}\text { Diabetes, IFG, IGT } \\
\text { or insulin resis- } \\
\text { tance and at least } \\
\text { two of the below }\end{array}$ & $\begin{array}{l}\text { At least three of the } \\
\text { below }\end{array}$ & $\begin{array}{l}\text { Waist } \geq 80 \mathrm{~cm} \\
\text { (depending on } \\
\text { ethnicity) and at } \\
\text { least two of the } \\
\text { below }\end{array}$ & $\begin{array}{l}\text { At least three of the } \\
\text { below }\end{array}$ \\
\hline $\begin{array}{l}\text { Waist/hip ratio }> \\
0.85 \text { and } / \text { or } \\
\text { BMI }>30 \mathrm{~kg} / \mathrm{m}^{2}\end{array}$ & Waist $>88 \mathrm{~cm}$ & & Waist $>88 \mathrm{~cm}$ \\
\hline \multirow[t]{2}{*}{$\begin{array}{l}\text { Triglycerides } \geq 1.7 \\
\mathrm{mmol} / 1 \mathrm{and} / \mathrm{or} \\
\mathrm{HDL} \leq 1 \mathrm{mmol} / 1\end{array}$} & $\begin{array}{l}\text { Triglycerides } \geq 1.7 \\
\text { mmol/1 or treat- } \\
\text { ment }\end{array}$ & $\begin{array}{l}\text { Triglycerides } \geq 1.7 \\
\text { mmol/1 or treat- } \\
\text { ment }\end{array}$ & $\begin{array}{l}\text { Triglycerides } \\
\geq 1.7 \mathrm{mmol} / 1\end{array}$ \\
\hline & $\begin{array}{l}\mathrm{HDL}<1.3 \mathrm{mmol} / 1 \\
\text { or treatment }\end{array}$ & $\begin{array}{l}\mathrm{HDL}<1.3 \mathrm{mmol} / 1 \\
\text { or treatment }\end{array}$ & $\mathrm{HDL}<1.3 \mathrm{mmol} / 1$ \\
\hline $\begin{array}{l}\text { Microalbuminuria } \\
>20 \mu \mathrm{g} / \mathrm{min}\end{array}$ & $\begin{array}{l}\text { fp-glucose } \geq 5.6 \\
\text { mmol/l or treat- } \\
\text { ment }\end{array}$ & $\begin{array}{l}\text { fp-glucose } \geq 5.6 \\
\text { mmol/1 or type } 2 \\
\text { diabetes }\end{array}$ & $\begin{array}{l}\text { fp-glucose } \geq 6.1-7 \\
\text { mmol/1 and/or } 2-h \\
\text { OGTT } 7.8-11 \\
\text { mmol/1 }\end{array}$ \\
\hline $\begin{array}{l}\text { Blood pressure } \\
\geq 140 / 90 \mathrm{mmHg}\end{array}$ & $\begin{array}{l}\text { Blood pressure } \\
\geq 130 / 85 \mathrm{mmHg}\end{array}$ & $\begin{array}{l}\text { Blood pressure } \\
\geq 130 / 85 \mathrm{mmHg}\end{array}$ & $\begin{array}{l}\text { Blood pressure } \\
\geq 130 / 85 \mathrm{mmHg}\end{array}$ \\
\hline
\end{tabular}

Abbreviations: $\mathrm{IFG}=$ Increased fasting glucose; $\mathrm{IGT}=$ impaired glucose tolerance; $\mathrm{fp}=$ fasting plasma; OGTT $=$ oral glucose tolerance test $\mathrm{HDL}=$ high-density lipoprotein.

\section{Cardiovascular consequences of PCOS}

Even at young age, women with PCOS carry a number of independent risk factors for cardiovascular disease (CVD) such as obesity [13, 76-78], changes in lipid profile [9-11], decreased fibrinolytic capacity $[14,15]$, increased inflammatory markers [79-81] and, a labile control of blood pressure [82].

In addition, women with PCOS display signs of endothelial dysfunction, which is an early event in the development of atherosclerosis that precedes plaque formation and clinical disease. Endothelial function is evaluated in PCOS patients, mostly by measuring post-ischemic flow mediated dilatation of the brachial artery by high-resolution ultrasonography and by measuring arterial stiffness with pulse wave velocity [83-89]. Women with PCOS also display signs of sub-clinical atherosclerosis at young age $[13,76-78,86,90$ 92].

Two relatively small long-term follow-up studies of women with PCOS with prior history of ovarian wedge resection indicate that these patients suffer an 
increased risk of myocardial infarction during the menopause [12, 93] and have an increased prevalence of coronary artery disease already in the perimenopausal period [93]. Register-based long-term follow-up studies suggest an increased prevalence of stroke [94] but morbidity and mortality from coronary heart disease among women with PCOS is not as high as predicted $[94,95]$. More recently, postmenopausal women with a retrospective diagnosis of PCOS are reported to have more angiographic coronary artery disease and lower cumulative five-year cardiovascular event-free survival than women without clinical features of PCOS [96] and postmenopausal mothers of PCOS patients have a higher prevalence of cardiovascular events than controls [44].

\section{Fibrinolysis}

Disturbances in the fibrinolytic system are known predictors for future CVD. Plasminogen activator inhibitor 1 (PAI-1) has a main role in the fibrinolytic system by inhibiting the tissue plasminogen activator (tPA). Tissue plasminogen activator (tPA) converts inactive plasminogen to plasmin and promotes degradation of fibrin, whereas, PAI-1 regulates fibrinolysis by inhibiting tPA [97] through forming an inactive complex (Figure 2).

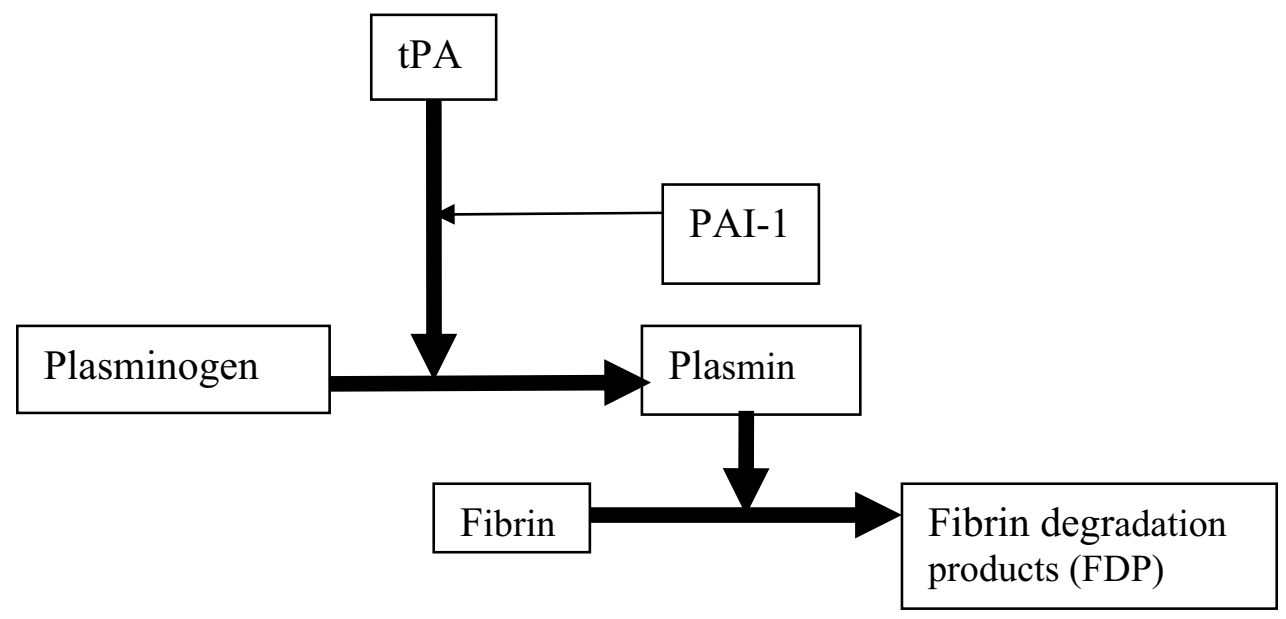

Figure 2. Simplified schematic description of the fibrinolytic system. Thin arrows indicate inhibition and bold arrows indicate activation.

Increased mass concentration of tPA, as a marker of endothelial disturbances, is possibly a better predictor for coronary heart mortality [98] than PAI-1 activity and is specifically associated with myocardial infarction in young women [99]. 
The triad obesity, raised triglycerides and, raised insulin levels is the most consistent predictor of impaired fibrinolysis and is often found in PCOS women [15, 100-103]. Earlier studies on PCOS women suggest both increased and normal levels of PAI-1 activity [15, 100-103], while studies on tPA-mass in PCOS patients are less ambiguous with increased levels [104106], although at least one study reported unchanged levels [107]. As most

studies on fibrinolytic activity in women with PCOS are limited in size it is still unclear if lean women with PCOS have disturbances in the fibrinolytic system.

\section{Obesity in PCOS patients}

Overweight and obesity is common among PCOS patients. No precise determinations of the prevalence of overweight among women with PCOS have been made in Sweden but it is estimated approximately half of Swedish PCOS women are overweight. Worldwide, the prevalence of overweight among PCOS patients ranges between $38 \%$ and $88 \%$ depending on the study population and the diagnostic criteria used (105).

Obesity (BMI $>30 \mathrm{~kg} / \mathrm{m}^{2}$ ) is reported to be prevalent in $10-38 \%$ of women with PCOS $[30,32,108]$, and, the prevalence of PCOS is increased in obese women where $28 \%$ are reported to fulfill criteria for PCOS in contrast to approximately $5 \%$ in normal weight women [109].

As a result of the co-existing hyperandrogenism, overweight in PCOS patients is often of the abdominal type [49]. The PCOS phenotype with oligomenorrhea and PCO, according to the ESHRE/ASRM criteria, appears associated with a lower prevalence of overweight/obesity than PCOS phenotypes where hyperandrogenism is a prerequisite [20,59].

However, whether women with PCOS are more prone to develop obesity or less able to lose weight than other women is unclear although findings indicate PCOS patients may be worse off in this respect [110]. Appetite is regulated by numerous factors, including the two gastrointestinal hormones ghrelin and cholecystochinin. Ghrelin stimulates appetite, whereas, cholecystochinin decrease appetite. Androgen levels play a role in this regulation, as high levels of testosterone are associated with decreased levels of cholecystochinin [111] and increased levels of ghrelin [112].

\section{Inflammatory markers}

Adipose tissue is an endocrine and autocrine organ [113] that produces and releases hormones, pro- and anti-inflammatory cytokines and chemoattractant cytokines (chemokines). Some of these proinflammatory molecules can be active participants in the development of insulin resistance and the increased risk of cardiovascular disease associated with obesity [114]. Central abdominal adiposity is a risk factor for metabolic disturbances and especially 
visceral fat accumulation is associated with insulin resistance and CVD [115]. The link between central adiposity and subsequent risk of CVD may be mediated through increased production of inflammatory markers in adipose tissue.

Macrophages are an important source of inflammation and adipose tissue in obesity is characterized by macrophage infiltration [116]. Increased macrophage infiltration can be caused by different chemokines attracting inflammatory cells to adipose tissue. One such example is chemokine (C-C motif) ligand 2 (CCL2) (also known as monocyte chemoattractant protein-1, MCP-1) and its cognate receptor chemokine receptor 2 (CCR2), both of which contribute to systemic insulin resistance, macrophage infiltration and, maintenance of macrophages in the adipose tissue [116, 117].

In adipose tissue, the expression and release of proinflammatory cytokines, such as macrophage migration inhibitory factor (MIF), tumor necrosis factor$\alpha($ TNF- $\alpha$ ) and, interleukin-18 (IL-18), is increased in obese adipose tissue [118-120]. Expanded adipose tissue mass of obese people is, directly or indirectly, correlated to an increased level of circulating inflammatory markers [121]. Circulating markers of inflammation, including CCL2, MIF and, highsensitive C-reactive protein (hs-CRP), are elevated in overweight PCOS women in comparison with weight-matched controls [79-81]. However, no studies concerning inflammatory markers in adipose tissue have been conducted in PCOS patients.

\section{Weight-reducing treatment}

Weight reduction is the primary intervention target in overweight or obese women with PCOS and rapid weight loss may be mandatory before a planned pregnancy or before fertility treatment can be initiated. Weight loss of $5-10 \%$ of weight in overweight women with PCOS through energy restriction can reduce circulating insulin levels and hyperandrogenism [71, $122,123]$ and improve menstrual cyclicity $[124,125]$, fertility and, cardiovascular disease risk factors [122].

Lifestyle modification focusing predominantly on diet and exercise behavior is considered the preferred first-line weight-reduction treatment for obese PCOS [124]. However, there is lack of consensus on the best nutritional management of obesity, in general, and for women with PCOS in particular [126] and diet recommendations for PCOS patients are most often based on local guidelines. Exercise appears equally effective as diet for reproductive outcomes in PCOS patients [127], as the addition of exercise to an energy-restricted diet improves body composition but has no additional effects on improvements in cardiometabolic, hormonal and, reproductive outcomes relative to diet alone [128].

When this thesis was planned, there was hope metformin would be the "all-in-one" drug for treatment of PCOS, including weight reduction in 
obese subjects. Metformin, which is still one of the most widely used drugs for treating PCOS, has positive effects on a number of metabolic parameters such as insulin resistance, fasting insulin levels, blood pressure and, lowdensity lipoprotein levels (LDL) [129]. However, the effect of metformin as a weight-reducing agent in obese subjects with PCOS is discouraging [129131]. The negative results from randomized clinical trials on metformin treatment in PCOS patients, together with the need for weight reduction in obese PCOS patients, prompted the evaluation of other anti-obesity drugs in this group of patients.

Two weight reducing drugs were available on the market at the time of the study: orlistat and sibutramine. Orlistat inhibits gastric and pancreatic lipases in the lumen of the gastrointestinal tract to decrease systemic absorption of dietary fat [132]. Studies on orlistat in combination with life style intervention show better weight loss than placebo and lifestyle intervention $[133,134]$. Sibutramine, on the other hand, acts by inhibiting the reuptake of serotonin and noradrenalin in the central nervous system appetite center, thus increasing satiety [135]. Compared to placebo, sibutramine induces more pronounced body weight reduction of between $5 \%$ and $10 \%$ in obese patients [136-139]. As with other anti-obesity drugs, the combined effect of lifestyle modification and sibutramine treatment is more effective than with just sibutramine treatment $[138,140]$. Sibutramine had also been evaluated with promising results in two open-label studies on patients with PCOS [141, $142]$.

All weight reduction treatments rely on concomitant life style interventions such as dietary recommendations and exercise [143] and as lifestyle interventions may be equally effective as only sibutramine treatment [138], a life-style modification treatment arm was incorporated into the clinical trial.

However, the results of this thesis must be interpreted in the light of current developments. The European Medicines Agency has recently recommended the suspension of the marketing authorization of sibutramine. This recommendation followed a safety review of preliminary data from the SCOUT-study [144]. The SCOUT study reported on 9800 obese or overweight patients with known cardiovascular disease who had been treated with sibutramine or placebo for a six-year period. Among patients treated with sibutramine, an increased risk of serious, non-fatal cardiovascular events, such as stroke or myocardial infarction was apparent: weight reduction, on the other hand, was modest with long-time treatment. 


\section{AIMS}

To estimate the prevalence of symptoms related to PCOS in a populationbased sample of Swedish women.

To evaluate if lean and over-weight/obese PCOS patients had disturbed fibrinolysis, as measured by PAI-1 activity and mass concentration of tPA in comparison with healthy control subjects.

To evaluate if lean and over-weight/obese PCOS patients displayed increased adipose tissue expression of inflammatory markers in comparison with healthy control subjects.

To examine the efficacy of sibutramine combined with brief lifestyle modification for weight reduction in over-weight and obese women with PCOS. 


\section{Materials and Methods}

\section{Patients and design \\ PCOS diagnosis}

In Paper I, PCOS was defined according to NIH criteria [16], otherwise the Rotterdam criteria were used in the thesis [2]. The diagnostic procedures in Paper I are described in more detail below.

In Papers II-IV, two out of three features had to be present for the PCOS diagnosis. The three features were: 1) oligomenorrhea with eight or fewer menstruations in the previous 12 months or amenorrhea; 2) clinical and/or biochemical signs of hyperandrogenism, such as testosterone $>2.7 \mathrm{nmol} / \mathrm{l}$, elevated DHEAS (according to reference range at participating clinics), free androgen index $\geq 5.0$, or hirsutism ( $>7$ on the Ferriman and Gallway scale); and, 3) polycystic ovaries on ultrasound examination ( $>12$ follicles 2 to 9 $\mathrm{mm}$ in diameter and/or increased ovarian volume $(>10 \mathrm{ml})$ ). PCOS diagnosis implied no evidence of thyroid disease (normal thyroid-stimulating hormone (TSH)), adrenocortical dysfunction (normal 17-hydroxyprogesterone) or, hyperprolactinemia (prolactin $<30 \mathrm{ug} / \mathrm{ml}$ ) was present.

\section{Paper I}

Data from the Northern Sweden component of the WHO MONICA study was used [145]. The information was collected during a population-based survey in 2004: 1000 men and 1000 women were invited to participate, and among women, participation rate was $78 \%$. The target population in the two most Northern counties of Sweden was 312,000 and subjects were randomly selected from population registers and stratified for age (25-74 years) and gender. For the purpose of the study, only females less than 40 years of age were included. Pregnant women and women who used hormonal contraceptives were excluded in the primary analysis. As the prevalence of PCOS may be increased among combined oral contraceptive users, these women were analyzed separately. A flow-chart for the study population from Paper I is presented in Figure 3. 


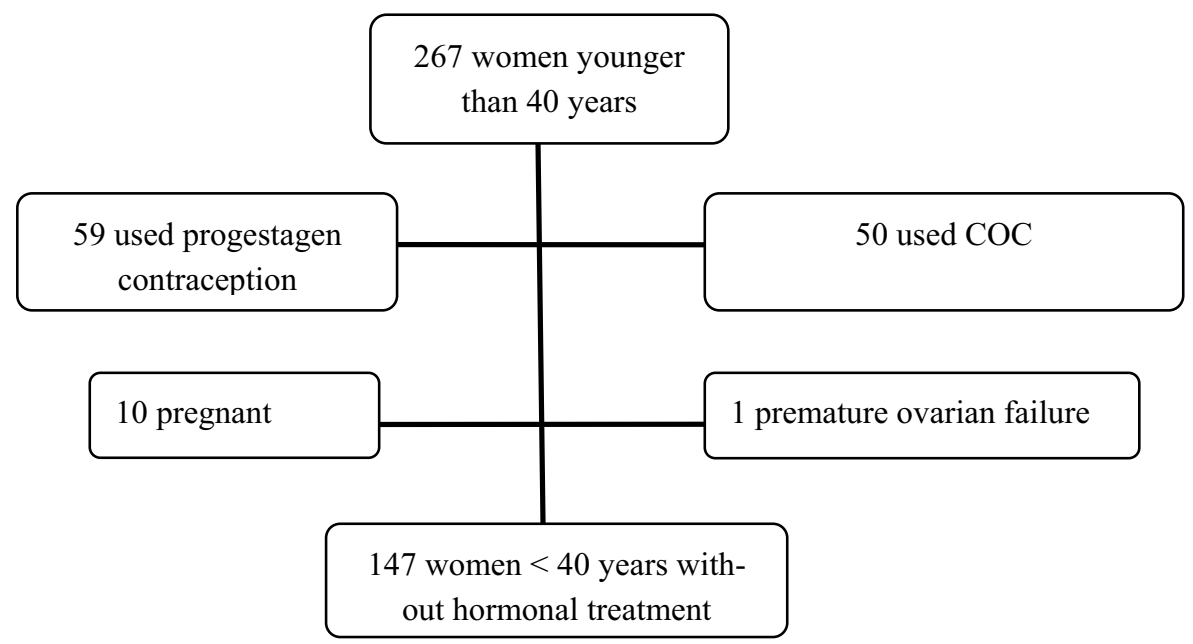

Figure 3. Study population from Paper I.

To evaluate reproductive status and PCOS-related symptoms, the women were asked three questions:

1) Do you still have regular menses? Response alternatives were: a) yes, regularly; b) sometimes, but not as regular as before; c) I have not had any menses for the last six months; d) I'm pregnant.

2) Has your menstrual cycle length, at any time during the last two years, been more than 35 days (yes/no)?

3) Do you have excessive growth of body hair in comparison with other women of your age (yes/no)?

Biochemical hyperandrogenism was evaluated through testosterone and SHBG measurements.

For further evaluation of COC users, two additional questions were used:

4) What contraceptive method have you been using during the last year (multiple choices possible)? Response alternatives were: a) have not used any contraception; b) combined oral contraceptives (COC); c) oral progestagens; d) progestagenic intrauterine device; e) progestagen implants; f) progestagen injections; g) other methods.

5) If currently on combined oral contraceptives, how were your menstrual cycles during the year before you started with COC? Response alternatives were: a) regular; b) irregular; c) did not have any menses.

From the responses and the calculated free androgen index, subjects were grouped into four different categories: oligomenorrhoic subjects; hyperandrogenic subjects; oligomenorrhoic and hyperandrogenic subjects; and, control subjects. 


\section{Paper II}

For this study, 135 patients with PCOS and 81 healthy controls were included. The PCOS patients were recruited from the Department of Obstetrics and Gynecology at Sunderby Hospital, Umeå University Hospital, Umeå, , and Uppsala University Hospital, Uppsala, while seeking medical care for oligomenorrhea and/or hirsutism. PCOS was defined according to the Rotterdam criteria; however, due to the increasing controversy on possibly milder PCOS phenotypes, a separate analysis was conducted on women diagnosed according to the NIH criteria [16].

The control subjects were recruited through advertisements in local newspapers in the study regions or from population-based registers. Healthy control status was assessed by careful menstrual history, laboratory work-up and, transvaginal ultrasound. Control subjects had regular menstrual cycles, normal androgen levels and, no signs of polycystic ovaries on transvaginal ultrasound.

\section{Paper III}

Twenty overweight PCOS patients $\left(\mathrm{BMI}>27 \mathrm{~kg} / \mathrm{m}^{2}\right)$ [65], ten normal weight PCOS patients $\left(\mathrm{BMI}<25 \mathrm{~kg} / \mathrm{m}^{2}\right.$ ) and twenty over weight controls (BMI > 27 $\mathrm{kg} / \mathrm{m}^{2}$ ) were included in the study. The rationale for the BMI limits chosen was based on a previous study [65] indicating that insulin resistance is prevalent at lower BMI in PCOS patients than in healthy women. The PCOS patients were recruited from the outpatients ward at the Department of Obstetrics and Gynecology at Sunderby Hospital, Umeå University Hospital and Uppsala University Hospital. The overweight PCOS patients were included from Paper IV.

\section{Paper IV}

Fifty PCOS patients were screened for this investigator-initiated, multicenter, double-blind, randomized, parallel-group clinical trial comparing daily sibutramine $15 \mathrm{mg}$ (Abbot Scandinavia, Sollentuna, Sweden) with placebo (Apoteket Production and Laboratories, Tillverkningsenheten, Stockholm, Sweden). Patients were recruited at the gynecological departments at Sunderby Hospital, Umeå University Hospital, Uppsala University Hospital, Läkarhuset Björnen, Piteå, and Lund University Hospital, Sweden. The study was conducted in 2005-2006. A flow-chart of the study population of Paper IV is presented in Figure 4. 


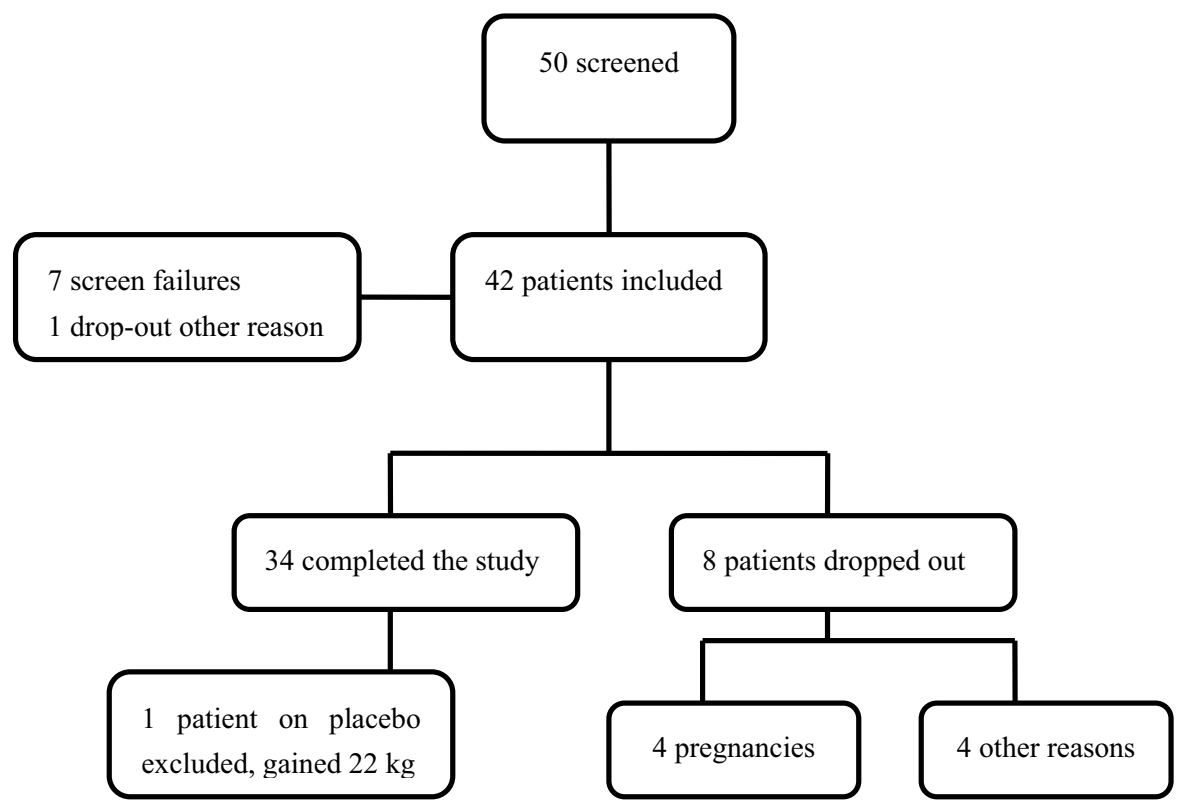

Figure 4. Study population in Paper IV.

Exclusion criteria for the study were ongoing or planned pregnancy, lactation and, use of hormonal treatment six months prior to study start. In addition, a number of contraindications for use of sibutramine were evaluated including hypertension (> 140/90 mmHg), for details see Paper IV.

Fifty patients were screened for the study. Among these, eight patients did not fulfill the inclusion criteria for participation in the study: 42 patients were included in the study.

The treatment period lasted 24 weeks. All patients received lifestyle modification in the form of dietary and physical activity advice. Subjects were advised to eat three regular meals every day and to reduce the intake of fat in favor for carbohydrates. All subjects were given a step-recorder and encouraged to walk a minimum of 10,000 steps a day, most days of the week. Homework assignments were also given, where food-intake, reason for food intake and physical activity were recorded.

The packing and randomization of treatment was done by Apoteket Production and Laboratories, Stockholm, Sweden. Randomization codes were kept secret at the Pharmacy at Uppsala University Hospital until completion of the study. Compliance was assessed by counting the remaining capsules at each visit. Study visits took place at baseline and at weeks 2, 6, 10, 14, 18, 22 , and 24. At each visit, weight, blood pressure and, heart rate and adverse 
effects from treatment and concomitant medication were assessed. Urinary pregnancy tests were taken from each subject before the start of the study, at week 14, and at the end of the study. Each woman was advised to use nonhormonal contraception throughout the study and to record vaginal bleeding on a bleeding chart, where absence of bleeding, spotting or, vaginal bleeding was recorded daily.

\section{Methods}

\section{Anthropometric measures, Papers I-IV}

Subjects were weighed on an electronic scale, in light clothes and no shoes: weight was measured to the nearest $0.2 \mathrm{~kg}$. Height without shoes was measured to the nearest centimeter. Body mass index (BMI) was calculated as weight $(\mathrm{kg})$ divided by height $\left(\mathrm{m}^{2}\right)$. For all participants, the waist and hip were measured in a standing position with the feet fairly close together: waist circumference was measured midway between the lower rib margin and iliac crest and the hip was measured at the maximum circumference over the buttocks and to the nearest 0.0 or $0.5 \mathrm{~cm}$. Blood pressure was measured twice in every person after a five-minute rest in a sitting position. The mean value of the two measurements was used in the study.

\section{Blood samples, Papers I-IV}

All blood samples in papers II - IV were drawn between 08.00 and 08.30 after overnight fasting and stored at $-20^{\circ} \mathrm{C}$ until analyzed. In Paper I, blood samples were drawn after at least a 4-hour fast.

The blood samples for fibrinolytic activity were collected in vacuum tubes (Stabylite ${ }^{\circledR}$, Biopool, Umea, Sweden) and stored at $-70^{\circ} \mathrm{C}$ until analysis. PAI-1 activity and tPA activity were measured by a chromogenic substrate assay. The tPA activity was reported in Uml, by reference to the activity of the International tPA Standard, coded 86/670 (National Institute for Biological Standards and Control, Potters Bar, London). Similarly, the PAI-1 activity was given in arbitrary $\mathrm{U} / \mathrm{ml}$, where $1 \mathrm{U}$ of PAI-1 was defined as the amount of PAI-1 inhibiting $1 \mathrm{U}$ of the International tPA Standard (above). The plasma mass concentration of tPA and PAI-1 antigen were measured with an enzyme linked immunosorbent assay. The reagent kits for assay of mass tPA and PAI-1 antigen (TintElize ${ }^{\circledR}$ ) and tPA and PAI-1 activity (Chromolize ${ }^{\circledR}$ ) were purchased from Biopool AB, Umeå, Sweden.

Remaining analyses were performed at the department of Clinical Chemistry, Uppsala University Hospital with standardized techniques and are described in detail in each paper. 
FAI was calculated as [testosterone $(\mathrm{mmol} / \mathrm{L})]$ / [SHBG (nmol/L)] x 100 and HOMA-IR as [fasting insulin (mU/L)] x [fasting serum glucose $(\mathrm{mmol} / \mathrm{L})] /$ 22.5 [146].

\section{Fat biopsies}

Fat biopsies were taken in the skin area to the right of the umbilicus after a local anesthesia with prilocain $(10 \mathrm{mg} / \mathrm{ml})$ : approximately $1.5 \mathrm{~cm}^{2}$ of superficial subcutaneous adipose tissue was excised and snap frozen in liquid nitrogen and stored at $-70^{\circ} \mathrm{C}$ until assayed.

\section{RNA extraction, reverse transcription, and real-time PCR}

Total RNA was extracted from adipose biopsies with RNeasyLipid Tissue Mini Kit (QIAGEN, Hilden, Germany). The yield and purity were determined by spectrophotometer (ND-1000 spectrophotometer, NanoDrop Technologies, Wilmington, DE9) and RNA integrity was analyzed by $1 \%$ agarose gel electrophoreses in the presence of ethidium bromide. One microgram of RNA was reverse transcribed with TaqMan RT reagents (High Capacity cDNA Reverse Transcription kit, Applied Biosystems, Foster City, $\mathrm{CA}$ ) and RNase inhibitor (Applied Biosystems) at a final concentration of $1.0 \mathrm{U} / \mathrm{ml}$. Subsequently, specific mRNAs were run in duplicate on an ABI Prism 7900HT sequence detection system (Applied Biosystems) with Taqman Universal PCR Master Mix (Applied Bioosystems). Seven inflammation-related genes were included in the analyses, including the chemokine CCL2 and its receptor CCR2; the proinflammatory cytokines MIF, TNF- $\alpha$, and IL-18; and, the monocyte/macrophage markers CD14 and CD163. The TaqMan gene expression assays (Applied Biosystems) used were; CCL2 (Hs00234140_ml), CCR2 (Hs00356601_m1), MIF (Hs00236988_g1), TNF$\alpha$ (Hs00174128_m1), IL-18 (Hs999999040_ml), CD14 (Hs00169122_g1), CD163 (Hs01016657_ml), LRP10 (Hs00204094_ml), PPIA (Hs999999904_ml), and RPLP0 (Hs99999902_ml). The parameter cycle threshold $(\mathrm{Ct})$ was defined as the cycle number at which the fluorescence intensity exceeded a fixed threshold. Relative amounts of mRNA expression for target genes were calculated with the comparative Ct method $(\Delta \Delta t)$. Reference genes were evaluated by running LRP10, PPIA and RPLP0 on the full study cohort, and the NormFinder [147] algorithm identified RPLP0 as the best normalization gene. Thus, the expression of RPLP0 was used to normalize samples for the amount of cDNA used per reaction. 


\section{Results}

\section{Paper I}

Of the 267 women eligible for the study, 147 women less than 40 years without hormonal therapy or ongoing pregnancy were included.

Forty-four $(29.9 \%)$ women were classified as oligomenorrhoic, of these, 13 women reported no menses during the last six months. Seventeen women $(11.6 \%)$ were classified as hyperandrogenic; of these, nine women reported excessive body hair growth in the questionnaire, six had increased FAI only, and two women had increased FAI together with excessive hair growth. Seven (4.8\%) women were classed as both oligomenorrhea and hyperandrogenism. No cases with increased levels of prolactin, follicle stimulating hormone (FSH) or TSH were identified among the women presenting with oligomenorrhea and hyperandrogenism.

Subjects with only hyperandrogenism had increased weight and BMI and increased waist circumference and waist:hip ratio, compared to controls. Furthermore, subjects with oligomenorrhea and hyperandrogenism had increased weight, BMI, waist and hip circumferences and, increased systolic and diastolic blood pressures compared to controls (Table 3). Subjects with hyperandrogenism and oligomenorrhea more often reported a history of hypertension and gestational diabetes than control subjects did.

Table 3. Clinical and biochemical parameters in healthy women, women with symptoms of oligomenorrhea, hyperandrogenism and both.

\begin{tabular}{|c|c|c|c|c|}
\hline & $\begin{array}{l}\text { Controls } \\
(\mathrm{n}=86)\end{array}$ & $\begin{array}{c}\text { OM } \\
(n=44)\end{array}$ & $\begin{array}{c}\text { HA } \\
(n=10)\end{array}$ & $\begin{array}{c}\mathrm{OM} \text { and HA } \\
(\mathrm{n}=7)\end{array}$ \\
\hline Weight, kg & $68.8 \pm 13.0$ & $68.0 \pm 16.9$ & $78.3 \pm 15.2 *$ & $80.5 \pm 14.6^{*}$ \\
\hline $\mathrm{BMI}, \mathrm{kg} / \mathrm{m}^{2}$ & $24.8 \pm 4.4$ & $25.1 \pm 6.9$ & $28.0 \pm 4.4^{*}$ & $29.5 \pm 5.7^{*}$ \\
\hline Waist circumference, $\mathrm{cm}$ & $82 \pm 11$ & $82 \pm 15$ & $90 \pm 11 *$ & $91 \pm 16^{*}$ \\
\hline Hip circumference, $\mathrm{cm}$ & $98 \pm 9$ & $99 \pm 12$ & $104 \pm 9$ & $106 \pm 9$ \\
\hline Waist/hip ratio & $0.8 \pm 0.1$ & $0.8 \pm 0.1$ & $0.9 \pm 0.05^{*}$ & $0.8 \pm 0.1$ \\
\hline Systolic BP, mmHg & $110 \pm 11$ & $111 \pm 10$ & $115 \pm 9$ & $128 \pm 14 * *$ \\
\hline Diastolic BP, mmHg & $70 \pm 8$ & $70 \pm 10$ & $72 \pm 8$ & $82 \pm 7 * *$ \\
\hline
\end{tabular}




\section{Paper II}

Although PCOS patients and control subjects did not differ in BMI, linear regression models were preferred for all relevant analyses in Paper II to exclude the possibility subtle weight differences would affect the results. Furthermore, as PCOS patients were younger than control subjects, adjustment for age was necessary.

Lean PCOS patients did not differ from control subjects in PAI-1 activity or tPA mass, regardless of how PCOS diagnosis was established (for details see Paper II).

The results of stepwise multiple regression analyses with PAI-1 as the dependent variable in relation to PCOS diagnosis (ESHRE/ASRM), age, BMI and HOMA-IR in overweight subjects are presented in Table 4. In the final model, $40 \%$ of the variation in PAI-1 activity was explained by age, BMI, and HOMA-IR; whereas, PCOS diagnosis did not remain a significant explanatory factor in the regression model when BMI was included.

Table 4. Results of a stepwise multivariate regression analysis of PAI- activity in relation to other variables in overweight subjects $(n=126$, BMI $>25)$.

\begin{tabular}{lcccc}
\hline & Model 1 & Model 2 & Model 3 & Model 4 \\
Variable & $\beta$ & $\beta$ & $\beta$ & $\beta$ \\
\hline $\mathrm{R}^{2}$ & 0.05 & 0.12 & 0.28 & 0.40 \\
PCOS diagnosis & $0.23^{*}$ & 0.16 & 0.10 & 0.08 \\
Age & & $-0.27^{* *}$ & $-0.18^{*}$ & $-0.18^{*}$ \\
BMI & & & $0.42^{* * *}$ & $0.22^{*}$ \\
HOMA-IR & & & & $0.38^{* * *}$ \\
\hline P
\end{tabular}

$\beta=$ standardized regression coefficient

$* \mathrm{p}<0.05$

$* * \mathrm{p}<0.01$

$* * * \mathrm{p}<0.001$

The results of a stepwise regression analysis with tPA mass as the dependent variable in overweight subjects are presented in Table 5. In this model, PCOS diagnosis remained a significant independent explanatory variable for the variation in tPA mass concentration among overweight subjects, with an explanation rate of $23 \%$ in the final model. 
Table 5. Results of a stepwise multivariate regression analysis of tPA mass concentration in relation to other variables in overweight subjects $(n=126, B M I>25)$.

\begin{tabular}{lcccc}
\hline & Model 1 & Model 2 & Model 3 & Model 4 \\
Variable & $\beta$ & $\beta$ & $\beta$ & $\beta$ \\
\hline $\mathrm{R}^{2}$ & 0.04 & 0.06 & 0.19 & 0.23 \\
PCOS diagnosis & $0.21^{*}$ & $0.24^{* *}$ & $0.19^{*}$ & $0.17^{*}$ \\
Age & & 0.14 & $0.22^{*}$ & $0.22^{*}$ \\
BMI & & & $0.38^{* * *}$ & $0.23^{*}$ \\
HOMA-IR & & & & $0.25^{*}$ \\
\hline$\beta=$
\end{tabular}

$\beta=$ standardized regression coefficient.

$* \mathrm{p}<0.05$

$* * \mathrm{p}<0.01$

$* * * \mathrm{p}<0.001$

Similar regression models for PCOS patients diagnosed according to NIH criteria are presented in Tables 6 and 7. In these analyses, PCOS diagnosis remained an independent explanatory variable for both PAI-1 activity and tPA-mass in overweight women.

Table 6. A multivariate regression analysis of PAI-1 activity in 51 PCOS patients with hyperandrogenism $(\mathrm{FAI}>5.0)$ and 81 controls across a wide range of BMI.

\begin{tabular}{lcc}
\hline & $\mathrm{BMI}<25$ & $\mathrm{BMI}>25$ \\
$\mathrm{n}=53$ & $\mathrm{n}=79$ \\
\hline $\mathrm{R}^{2}$ & 0.50 & 0.15 \\
Age & $\beta$ & $\beta$ \\
BMI & -0.07 & -0.20 \\
HOMA-IR & 0.18 & 0.001 \\
PCOS diagnosis & $0.29 *$ & $0.41^{* *}$ \\
\hline B & 0.17 & $0.29 *$
\end{tabular}

$\beta=$ standardized regression coefficient

$* \mathrm{p}<0.05$

$* * \mathrm{p}<0.01$

$* * * \mathrm{p}<0.001$ 
Table 7. A multivariate regression analysis of tPA mass concentration in 51 PCOS patients with hyperandrogenism $(\mathrm{FAI}>5.0)$ and 81 controls across a wide range of BMI.

\begin{tabular}{lcc}
\hline & $\mathrm{BMI}<25$ & $\mathrm{BMI}>25$ \\
& $\mathrm{n}=53$ & $\mathrm{n}=79$ \\
\hline $\mathrm{R}^{2}$ & 0.39 & 0.34 \\
& $\beta$ & $\beta$ \\
Age & $0.45^{* *}$ & $0.33^{* *}$ \\
BMI & 0.18 & $0.41^{*}$ \\
HOMA-IR & 0.23 & 0.63 \\
PCOS diagnosis & 0.12 & $0.34^{*}$ \\
\hline
\end{tabular}

$\beta=$ standardized regression coefficient

$* p<0.05$

$* * \mathrm{p}<0.01$

\section{Paper III}

Relative amounts of adipose tissue expression of inflammatory markers in overweight and lean PCOS patients and in overweight controls are displayed in Figure 5. Overweight PCOS patients and overweight control subjects had more increased relative amounts of CCL2, CCR2, TNF- $\alpha$, IL-18, CD14 and, CD163 adipose tissue expression than lean PCOS patients. There were no significant differences between overweight PCOS patients and overweight control subjects in relative adipose tissue expression of any of the inflammatory markers. MIF expression did not differ between groups. 


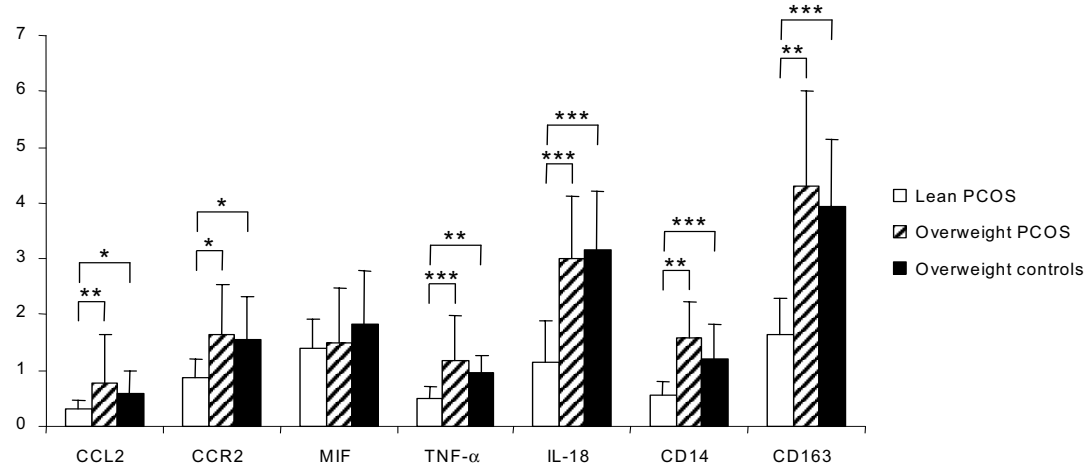

Figure 5. Inflammatory gene expression (mean \pm SD) in abdominal superficial subcutaneous adipose tissue in lean PCOS patients (white bars, $\mathrm{n}=10$ ), overweight PCOS patients (diagonal lined bars, $n=20$ ), and overweight control subjects (black bars, $\mathrm{n}=20$ ). Expression levels are relative to the RPLP0 normalization gene. Abbreviations: chemokine ligand 2 (CCL2), chemokine receptor 2 (CCR2), macrophage migration inhibitory factor (MIF), tumor necrosis factor $\alpha$ (TNF- $\alpha$ ), interleukin 18 (IL-18), ${ }^{*} \mathrm{p}<0.05, * * \mathrm{p}<0.01$ and, $* * * \mathrm{p}<0.001$.

Adipose tissue markers of inflammation, except for MIF, were correlated with most metabolic risk markers within the PCOS group (Table 8). CCR2, IL-18, CD14, and CD163 expression was negatively correlated with serum concentrations of SHBG. Free androgen index correlated with CD 163 but not with any other inflammatory marker in adipose tissue.

BMI was the main explanatory variable for adipose tissue inflammatory markers in PCOS patients. On adjustment for age and BMI, only the positive correlations between adipose mRNA expression of CCR2 and fasting glucose levels and, CCL2, TNF- $\alpha$, and CD14 with systolic blood pressure remained (for details see Paper IV). 
Table 8. Bivariate correlations between adipose tissue expression of CCL2, CCR2, MIF, TNF $\alpha$, IL-18, CD14 and, CD163 and selected anthropometric/metabolic variables in women with PCOS $(n=30)$.

\begin{tabular}{lccccccccccc}
\hline & BMI & Waist & Glucose & Insulin HOMA-IR & TG & $\begin{array}{c}\text { BP } \\
\text { sys- } \\
\text { tolic }\end{array} \begin{array}{c}\text { BP } \\
\text { dia- } \\
\text { stolic }\end{array}$ & FAI & SHBG \\
\hline CCL2 & $0.52^{* *}$ & $0.42^{*}$ & $0.55^{* *}$ & 0.34 & 0.35 & 0.33 & $0.52^{* *}$ & 0.28 & 0.20 & -0.24 \\
CCR2 & $0.52^{* *}$ & $0.42^{*}$ & $0.59^{* *}$ & $0.50^{* *}$ & $0.50^{* *}$ & $0.50^{* *}$ & 0.12 & 0.30 & 0,24 & $-0.42^{*}$ \\
MIF & -0.08 & -0.03 & 0.02 & 0.02 & 0.02 & 0.06 & -0.07 & -0.18 & -0.14 & 0.06 \\
TNF- $\alpha$ & $0.55^{* *}$ & $0.48^{* *}$ & $0.58^{* *}$ & $0.42^{*}$ & $0.41^{*}$ & $0.46^{* *}$ & $0.65^{* *}$ & $0.52^{* *}$ & 0.07 & -0.23 \\
IL-18 & $0.76^{* *}$ & $0.73^{* *}$ & $0.67^{* *}$ & $0.54^{* *}$ & $0.53^{* *}$ & $0.57^{*}$ & $0.47^{*}$ & $0.55^{* *}$ & 0.32 & $-0.42^{*}$ \\
CD14 & $0.78^{* *}$ & $0.75^{* *}$ & $0.67^{* *}$ & $0.55^{* *}$ & $0.54^{* *}$ & $0.56^{* *}$ & $0.53^{* *}$ & $0.58^{* *}$ & 0.34 & $-0.41^{*}$ \\
CD163 & $0.77^{*}$ & $0.68^{* *}$ & $0.61^{* *}$ & $0.50^{* *}$ & $0.50^{* *}$ & $0.50^{* *}$ & $0.52^{* *}$ & $0.55^{* *}$ & $0.38^{*}$ & $-0.45^{*}$ \\
\hline
\end{tabular}

${ }^{*} \mathrm{p}<0.05$, and ${ }^{* *} \mathrm{p}<0.01$

\section{Paper IV}

Thirty-four women with PCOS completed the clinical trial. One subject on placebo was excluded prior to statistical analyses as she developed an eating disorder during the course of the study. Four patients dropped out during the study due to positive pregnancy tests: three of the pregnant women were treated with sibutramine and one with placebo. Four patients dropped out for personal reasons. 


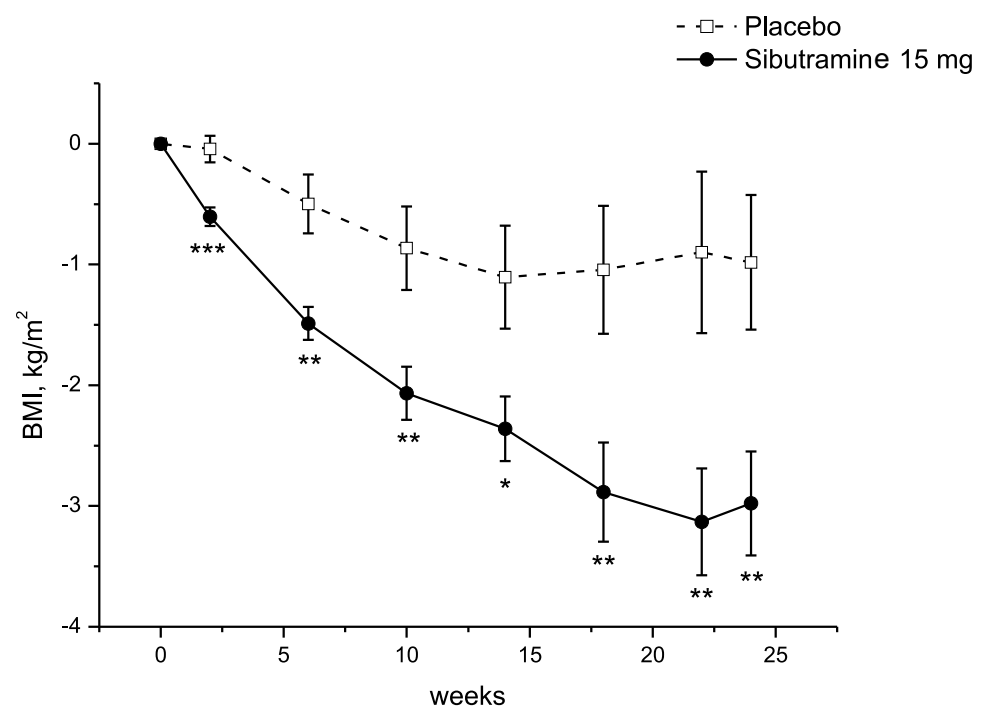

Figure 6. Mean \pm SEM BMI reduction after 24 weeks of treatment with sibutramine $15 \mathrm{mg}$ daily $(\mathrm{n}=21)$ and placebo $(\mathrm{n}=20)$, both together with brief life style intervention. Patients dropping out of the study are kept in the analysis as far as possible. Compared to placebo, sibutramine treatment resulted in reduced BMI (main effect of treatment: $F(1,30)=11.18 ; \mathrm{p}<0.01$, treatment by time interaction $\mathrm{F}(1,30)=6.00 ; \mathrm{p}$ $<0.05)$ ).

After six months, the sibutramine group had a mean weight loss of $7.8 \pm 5.1$ $\mathrm{kg}$ (range 5.7 to $-14.3 \mathrm{~kg},-9.0 \%$ ) and the placebo group a mean loss of $2.8 \pm$ $6.2 \mathrm{~kg}$ (range 7.0 to $-15.7 \mathrm{~kg},-1.7 \%$ ) (Figure 6). Sibutramine treatment resulted in significant decreases in ApoB ( $\mathrm{p}<0.01)$, ApoB/ApoA ratio ( $p$ $<0.05)$, triglycerides $(p<0.05)$, cystatin $C$ levels $(p<0.05)$ and, free androgen index $(p<0.05)$; whereas, SHBG levels increased $(p<0.05)$. The reduction in triglycerides, cystatin C, FAI and the increase of SHBG were greater among subjects treated with sibutramine than in those treated with placebo (Table 9). 
Table 9. Metabolic and hormonal parameters before and after sibutramine and placebo treatment.

\begin{tabular}{|c|c|c|c|c|}
\hline & \multicolumn{2}{|c|}{$\begin{array}{l}\text { Sibutramine } \\
\text { mean } \pm \mathrm{SD}\end{array}$} & \multicolumn{2}{|c|}{$\begin{array}{c}\text { Placebo } \\
\text { mean } \pm \text { SD }\end{array}$} \\
\hline & $\begin{array}{l}\text { Baseline } \\
(\mathrm{n}=21)\end{array}$ & $\begin{array}{l}6 \text { month } \\
(\mathrm{n}=17)\end{array}$ & $\begin{array}{l}\text { Baseline } \\
(\mathrm{n}=20)\end{array}$ & $\begin{array}{l}6 \text { month } \\
(\mathrm{n}=16)\end{array}$ \\
\hline $\begin{array}{l}\text { Triglycerides, } \\
\mathrm{mmol} / \mathrm{L}\end{array}$ & $1.68 \pm 0.87$ & $1.32 \pm 0.62^{\mathrm{a}, \mathrm{c}}$ & $1.66 \pm 1.00$ & $1.80 \pm 1.09$ \\
\hline ApoA-I, g/L & $1.36 \pm 0.14$ & $1.42 \pm 0.22$ & $1.43 \pm 0.13$ & $1.47 \pm 0.16$ \\
\hline ApoB, g/L & $1.01 \pm 0.26$ & $0.94 \pm 0.26^{\mathrm{b}}$ & $0.99 \pm 0.38$ & $0.96 \pm 0.33$ \\
\hline ApoB/ApoA & $0.75 \pm 0.20$ & $0.68 \pm 0.21^{\mathrm{a}}$ & $0.69 \pm 0.27$ & $0.67 \pm 0.25$ \\
\hline Glucose, $\mathrm{mmol} / \mathrm{L}$ & $4.87 \pm 0.51$ & $4.74 \pm 0.52$ & $4.97 \pm 0.35$ & $5.00 \pm 0.54$ \\
\hline Insulin, $\mathrm{mU} / \mathrm{L}$ & $12.88 \pm 6.65$ & $13.07 \pm 9.09$ & $16.83 \pm 12.33$ & $19.42 \pm 15.03$ \\
\hline HOMA-IR & $2.81 \pm 1.63$ & $2.75 \pm 1.72$ & $3.86 \pm 3.21$ & $4.60 \pm 4.13$ \\
\hline Cystatin C, mg/L & $0.77 \pm 0.09$ & $0.74 \pm 0.10^{\mathrm{a}, \mathrm{c}}$ & $0.72 \pm 0.10$ & $0.75 \pm 0.08$ \\
\hline Hs-CRP, mg/L & $3.3 \pm 2.5$ & $4.1 \pm 6.1$ & $4.6 \pm 0.8$ & $6.0 \pm 6.6$ \\
\hline $\begin{array}{l}\text { Testosterone, } \\
\mathrm{nmol} / \mathrm{L}\end{array}$ & $2.08 \pm 0.87$ & $1.80 \pm 0.65$ & $2.68 \pm 1.10$ & $2.56 \pm 0.87$ \\
\hline SHBG, nmol/L & $37.1 \pm 15.8$ & $44.9 \pm 19.2^{\mathrm{a}, \mathrm{c}}$ & $32.6 \pm 3.0$ & $30.7 \pm 13.2$ \\
\hline
\end{tabular}

${ }^{a} \mathrm{p}<0.05$ compared with baseline values of the corresponding group, paired t-test.

${ }^{\mathrm{b}} \mathrm{p}<0.01$ compared with baseline values of the corresponding group, paired t-test.

${ }^{c}$ change from baseline significantly greater than in the placebo group, ANOVA with repeated measures (time by drug interaction), $\mathrm{p}<0.05$. 


\section{Discussion}

\section{Prevalence of PCOS}

In Northern Sweden, an estimated $4.8 \%$ of women of fertile age fulfill the criteria for PCOS, according to NIH criteria: this prevalence rate corresponded with other studies in Northern Europe [33, 148] and white women in the U.S. [31]. However, the prevalence rate for the Swedish population was lower than reported for Southern European women [30, 32], black American women [31] and Australian women [40], where prevalence rates for PCOS, according to NIH criteria, varies between $6.5-8.7 \%$. Less data is available from Asian populations but in a hospital-based sample [149], 2.2\% of Chinese women are reported to fulfill the NIH criteria for PCOS.

An Australian community-based study compares prevalence rates according to different PCOS criteria [40]. As only $39 \%$ of the women in the cohort consented to the transvaginal ultrasound examination, prevalence rates for the Rotterdam and AE-PCOS criteria are reported with and without approximations of expected PCO features. The estimated prevalence of PCOS was $8.7 \%$ according to NIH criteria, $11.9 \%$ according to the Rotterdam criteria and $10.2 \%$ according to AE-PCOS criteria: with the inclusion of imputed data, the prevalence rate increased to $17.8 \%$ for Rotterdam and to $12.0 \%$ for the AE-PCOS criteria. However, the approximation of ultrasound features for women declining the transvaginal ultrasound examination may be biased, as it can be assumed the majority of symptomatic women are more concerned about their health and, therefore, more inclined to be investigated. Furthermore, a recent community-based study from Sri Lanka [150] reports $6.3 \%$ of women of childbearing age have PCOS, according to the 2003 Rotterdam criteria

Hirsutism was not assessed by physicians nor was an ultrasonographic examination of the ovaries performed in this prevalence study: this could be considered a weakness of the study. Besides the inter-rater variability in hirsutism scorings, the feasibility of the Ferriman-Gallwey score is impaired as many women treat the symptoms prior to clinical evaluation; thus, it is unlikely an objective assessment of hirsutism would have yielded a more accurate measure of clinical hyperandrogenism. Furthermore, a simple symptom-based questionnaire may be useful for identifying women with an endocrine profile typical for PCOS $[33,150]$. In Sri Lanka, more than $90 \%$ of women with self-reported symptoms of oligo/amenorrhea and/or hirsutism 
were later shown to have PCOS [150]. A Finnish study reports polycystic ovaries were later detected in $18 \%$ of women reporting only hirsutism, in $48 \%$ of women reporting only oligomenorrhea, and in $70 \%$ of women reporting both symptoms [148]. As indicated in the Australian prevalence study it is difficult to include the transvaginal ultrasound in prevalence studies of PCOS as less than half of women are willing to undergo the examination [40].

Based on the few studies including transvaginal ultrasound for PCOS diagnosis, it is plausible more women in both the oligomenorrhea-only group and the hyperandrogenism-only group would be diagnosed as PCOS, if the ESHRE criteria were used [40, 150]. However, the ESHRE criteria would probably not have yielded more subjects at risk of metabolic syndrome, as findings of the metabolic syndrome are more frequently encountered in the PCOS patients defined according to the NIH criteria [18, 19].

Another limitation to the study was the causes for oligomenorrhea and hirsutism such as hypothyroidism and premature ovarian failure not being evaluated in all subjects, at least not in the published paper. However, no cases with increased levels of prolactin, FSH or, TSH were found among the women who presented with oligomenorrhea and hyperandrogenism.

The relevance of the PCOS diagnosis suggested in the present study was strengthened by the population-based sample and the metabolic changes identified in the group with both oligomenorrhea and hyperandrogenism. This group had increased weight, increased BMI, increased waist and hip circumferences and, higher systolic and diastolic blood pressure, compared to controls, and more frequently reported a history of hypertension and gestational diabetes. Metabolic derangements were identified in the hyperandrogenism-only and the oligomenorrhea and hyperandrogenism groups but not in the oligomenorrhea-only group. Increased free testosterone is consistently associated with increased systolic and diastolic blood pressures [151158]. Animal studies indicate the prohypertensive effect of androgens are mediated through increased vascular tone via upregulation of thromboxane A2 expression, norepinephrine, angiotensin II and endothelin-1 synthesis [159] : androgens may also influence blood pressure by affecting the reninangiotensin-aldosterone system [159].

Unpublished findings from the entire premenopausal cohort of women in the WHO-Monica sample indicate many women with PCOS may go undiagnosed and among women with free androgen index $>5$, less than $10 \%$ report excessive growth of body hair (Andersson et al., submitted).

PCOS women are at risk for developing metabolic disturbances [6], thus, it would be a health benefit to identify women with PCOS. Early identification may be beneficial, as lifestyle interventions can be implemented before metabolic disturbances develop. A simple symptom-based questionnaire can assist in detecting women with PCOS, but the addition of biochemical markers for hyperandrogenism yields additional information. 


\section{Fibrinolytic activity in women with PCOS}

The main finding of Paper II was that overweight women with PCOS displayed increased tPA mass in comparison with controls: this finding was consistent irrespective of diagnosis with Rotterdam criteria or NIH criteria. In addition, when biochemical NIH criteria were used for PCOS diagnosis, overweight women with PCOS displayed increased PAI-1 activity. No signs of derangement in fibrinolytic variables were detected in lean women with PCOS, irrespective of how the PCOS diagnosis was established.

These findings might elucidate some discrepancies regarding fibrinolytic activity in PCOS, as earlier studies indicate both increased PAI-1 activity $[15,100,101,160]$ and normal PAI-1 activity in PCOS patients $[102,103]$ [159]. Thus, it is plausible studies indicating no difference in PAI-1 activity have included a more heterogeneous population of PCOS patients with regard to hyperandrogenism. For example, Atiomo et al [102] do not assess biochemical hyperandrogenism and, in two studies [103, 159], only high testosterone is used for the assessment of hyperandrogenism. One prior study [100] uses increased FAI as the hyperandrogenism criterion in PCOS patients, while adjusting for BMI, and report increased PAI-1 activity in the PCOS group: this finding is in accordance with the findings of this study. The importance of free androgen index for PAI-1 activity is further strengthened by the finding that FAI, together with BMI and insulin resistance, was an independent explanatory variable for PAI-1 activity in women with PCOS.

Increased tPA mass concentration in overweight PCOS patients confirmed previous findings [104-107]. Among PCOS patients, tPA mass was influenced by age, BMI and, free androgen index. Mass concentration of tPA is considered a better predictor of cardiovascular mortality than PAI-1 activity after myocardial infarction [98], and tPA mass is associated with myocardial infarction in young women [99]. Thus, increased tPA mass concentration in overweight PCOS patients indicates that this group of women are at risk for cardiovascular disease. Among overweight PCOS patients, tPA mass was increased, independently of whether free androgen levels were included in the PCOS diagnosis or not: this finding suggested impaired fibrinolysis, as a marker for endothelial dysfunction, could also exist in patients with less severe hyperandrogenism (i.e. PCOS light).

Lean PCOS patients had similar tPA mass levels and PAI-1 activity as controls, and this finding remained when NIH-criteria were also applied, and was in accordance with another study on lean PCOS patients [107] ; although others report increased tPA mass and increased PAI-1 activity in lean PCOS patients $[15,100]$. A possible explanation for the discrepancies between the findings of this study and previous findings regarding lean PCOS patients is the ethnic differences between study populations. For example, Greek PCOS patients are more frequently carriers of the $4 \mathrm{G}$ allele in the 
4G5G polymorphism of the PAI-1 gene, and the presence of the 4G allele in the PAI-1 promoter region of the gene further increases PAI-1 levels [160].

In conclusion, overweight women with PCOS have impaired fibrinolysis, in particular if they also display objective biochemical markers of hyperandrogenism. However, there was no evidence lean PCOS patients carry this specific risk factor for cardiovascular disease. As PCOS is common in the population, identifying subjects at risk of future cardiovascular disease would be a health benefit for both the patient and the society.

Another important conclusion is that the Rotterdam criteria for PCOS diagnosis may be an improvement in the fertility setting, but is less valuable in the pursuit of long-term health risk and consequences of PCOS. Hyperandrogenism assessed by use of free androgen index could be included as a diagnostic criterion for PCOS when evaluating risk factors for cardiovascular disease in this specific group of patients. Independent of PCOS diagnosis, increased testosterone and decreased SHBG are strongly associated with a number of adverse cardiovascular disease risk factors in postmenopausal women, such as central adiposity, decreased HDL cholesterol levels and, increased systolic and diastolic blood pressures [151-154]. A recent nested case-control study of postmenopausal women [161] also suggests higher free androgen index is associated with CVD events such as first occurrence of nonfatal myocardial infarction, coronary revascularization, nonfatal stroke, coronary disease, or stroke death; although, this association is not independent of BMI and other cardiovascular risk factors. Besides a possible role of androgen hormones and SHBG in cardiovascular disease, low levels of SHBG are consistently linked to higher rates of diabetes [162, 163] and might contribute to a more adverse cardiovascular risk profile in women with diabetes $[164,165]$.

\section{Inflammatory markers in adipose tissue of PCOS women}

The gene expression pattern of inflammatory markers in abdominal superficial subcutaneous tissue was similar in overweight PCOS patients and overweight control subjects, whereas lean PCOS patients displayed lower expression of adipose inflammatory markers (Paper III). In accordance with this finding, most associations between markers of adipose tissue inflammation and variables of the metabolic syndrome in PCOS patients were lost when adjusted for age and BMI. Therefore, overweight or obesity, rather than the PCOS diagnosis per se, appeared to be the main explanatory variable for increased adipose inflammation in PCOS patients.

Serum concentrations of inflammatory markers such as CCL2 and CRP are increased in overweight PCOS patients, compared with weight-matched controls [81], and the inflammatory status is correlated with elevated androgen levels $[80,81]$. However, other studies have failed to display any differences in circulating TNF- $\alpha$ and IL- 6 between overweight controls and over- 
weight PCOS patients [166]. In contrast to previous studies of peripheral inflammatory markers in PCOS patients, increased circulating levels of hsCRP, CCL2, and IL-18 in overweight PCOS patients were not confirmed, probably due to a type II error. Similarly, the correlation between adipose expression of inflammatory markers and FAI or testosterone could not be demonstrated; although, as in other studies [80, 81], SHBG (as an indirect measure of hyperandrogenism) was negatively correlated with most of the inflammatory markers.

Support for a possible causal relationship between obesity-associated low-grade inflammation and metabolic impairment is gained from epidemiological data indicating an association of markers of systemic inflammation (i.e., CRP and IL-6) with insulin resistance and future risk of developing type 2 diabetes [167]. In agreement with other studies [118, 168-170], a pronounced effect of increased body mass on adipose expression of chemokines, pro-inflammatory cytokines, and inflammatory markers was found, although overweight PCOS patients did not differ from overweight controls. MIF expression was not influenced by fat mass, which was in agreement with unpublished data demonstrating MIF expression in subcutaneous fat depots is unaffected by fat mass, although apparently conflicting data on MIF from isolated human subcutaneous adipocytes correlating with BMI is reported [171]. The majority of adipose-secreted MIF originates from nonfat cells in obese women [34] and it is probable that the adipocyte isolation and culturing procedure per se influences the secretion pattern [172].

Preclinical studies provide evidence that ablation of the CCL2/CCR2 pathway improves insulin sensitivity in conjunction with reduced adipose tissue inflammation [173], and inhibition of CCR2 in obese mice improves insulin sensitivity and reduces macrophage content in adipose tissue [173]. Moreover, pharmacological inhibition of CCR2 in the early stage of obesity in $\mathrm{db} / \mathrm{db}$ mice ameliorates insulin resistance and hepatic steatosis [174]. A positive correlation between adipose tissue CCR2 gene expression and fasting serum glucose levels was determined, which was independent of age and BMI in the PCOS group. In diabetic patients, expression levels of CCR2, CD36 and, CD68 on monocytes are increased, and poor glycemic control is associated with high levels of serum CCL2 and circulating monocyte CCR2 [175]. However, the possible contribution of elevated adipose CCR2 to adipose tissue, as well as whole body, metabolic dysregulation in humans remains to be determined.

Adipokine secretion patterns may influence blood pressure parameters. In this respect, most focus is on endocrine factors such as leptin, which may activate the sympathetic nervous system, and adiponectin, which may and inhibit the sympathetic nervous system (reviewed in [176]). Among the adipose inflammation-related factors with endocrine (and paracrine) effects (i.e., CCL2, MIF, and IL-18,), CCL2 correlated with systolic blood pressure after adjustment for age and BMI. Similarly, adipose TNF- $\alpha$ (mainly 
autocrine/paracrine action) correlated with systolic blood pressure. As these molecules act on immune cells inducing local and systemic inflammation, endothelial and vascular function might be altered. Although systemic TNF$\alpha$ is suggested as an independent risk factor for elevated blood pressure in apparently healthy subjects [177], approximately one-third of the TNF- $\alpha$ values were below the limit of detection and the study was cross-sectional [177]. The adipose tissue contribution of TNF- $\alpha$ to the circulation has not been fully resolved and there is only a modest elevation of serum concentrations in obese patients [178].

The limited number of participants and the absence of a lean control group could be considered a limitation in Paper III. As the study did not include a lean control group, we could not determine whether lean PCOS patients deviated from weight-matched controls in terms of expression patterns of adipose tissue inflammatory markers. The inclusion of a lean control group would have enhanced understanding of how adipose tissue inflammation is influenced by hyperandrogenism and PCOS. Obtaining adipose tissue biopsies from only one anatomical location (abdominal superficial subcutaneous adipose tissue) was another limitation, as different adipose tissue depots have different profiles regarding inflammatory marker expression $[170$, $179,180]$.

In conclusion, fat mass rather than PCOS diagnosis per se appears the main determinant of increased inflammatory markers in adipose tissue. Further studies investigating the different clinical phenotypes of PCOS in terms of gene expression pattern of inflammatory markers in abdominal superficial subcutaneous tissue are warranted.

\section{Weight reduction treatment in women with PCOS}

The use of sibutramine together with lifestyle modification resulted in a greater weight loss in women with PCOS than for placebo and lifestyle modification alone (Paper IV). Women treated with sibutramine lost on average $7.8 \mathrm{~kg}(-9.0 \%)$ during treatment, compared to a weight loss of $2.8 \mathrm{~kg}$ ($1.7 \%$ ) in the placebo group. Successful weight loss after sibutramine treatment was associated with lower age and low SHBG levels at baseline. Although testosterone levels at baseline were not associated with weight reduction, this finding could indicate young women with pronounced hyperandrogenism would benefit from sibutramine treatment. The weight reduction obtained with sibutramine and lifestyle modification in women with PCOS was similar to previously reported weight reductions in other obese patient groups [137-140, 181, 182].

The importance of lifestyle modification in addition to anti-obesity treatments has been stressed. Wadden et al [138] present data indicating organized and intense lifestyle modification together with sibutramine treatment is more efficacious than sibutramine alone and that organized lifestyle modifi- 
cation alone is as powerful as sibutramine alone in reducing weight in obese subjects.

Both sibutramine and placebo treatment resulted in increased menstrual frequency but there was no difference between treatments: this finding was in agreement with other studies $[71,124,183]$ on weight loss in PCOS patients. The frequency of menstruations can be an indirect measurement of ovulation, although urinary luteinizing hormone kits or progesterone serum concentrations should preferably have been used to estimate the number of ovulatory cycles. With longer-term treatment and sustained weight reduction, further improvements in menstrual pattern could possibly be detected.

The European Medicines Agency (EMA) recently recommended the suspension of marketing authorization of sibutramine. This statement was initiated by a safety review of preliminary data from the SCOUT-study where 9800 obese or overweight patients with known cardiovascular disease were treated with sibutramine or placebo for a six-year period [144]. The SCOUTstudy concluded that patients treated with sibutramine have an increased risk of serious, non-fatal cardiovascular events, such as stroke and myocardial infarction and weight reduction was modest with long-time treatment. An EMA press release stated the 21 of January 2010; sibutramine should no longer be prescribed by doctors nor dispensed by pharmacists. At the time this thesis was written, the SCOUT data, upon which the recommendations are based, had not been published.

In the young and presumably otherwise healthy women with PCOS, improvements in lipid profile were obtained with sibutramine treatment. Sibutramine treatment resulted in lower levels of triglycerides, lower levels of ApoB and a lower ApoB/ApoA-1 ratio, which concurred with other findings for sibutramine treatment, where favorable effects on HDL-cholesterol and triglycerides and total:HDL cholesterol ratio are reported [181]. In addition, SHBG levels increased in the sibutramine group: increased SHBG levels result in decreased availability of biologically active free testosterone [184] and may be a marker of metabolic benefit, as low SHBG is associated with insulin resistance and high plasma insulin levels [185]. However, sibutramine did not have any beneficial effects on blood pressure, fat distribution or insulin sensitivity index in young women with PCOS. Finally, compliance to the contraceptive advice given at study inclusion was not always followed by the participants, as four women became pregnant during the course of the study.

The EMA recommendations have been heavily criticized by patient organizations and health care professionals. The patients who were included in the SCOUT study had known contra-indications for sibutramine use, and it can be argued these subjects would not have received treatment in clinical practice. However, according to the European authority, overweight and obese patients have an increased risk of cardiovascular events, and this is why the SCOUT study results are relevant in the clinic, even for patients 
without evident cardiovascular disease. These recommendations are a major drawback for women with PCOS (and other obese patients) who are in need of rapid weight reduction for the initiation of fertility treatment. These women are left with life-style intervention [122], orlistat [186] or, bariatric surgery [187]. However, as the full report of the SCOUT study is not yet available, a comprehensive assessment of the result is not possible.

In conclusion, sibutramine in combination with lifestyle intervention can reduce weight in overweight and obese women with PCOS. However, the use of sibutramine has been precluded because of recommendations from the European Medicines Agency. Further recommendations on possible usability in younger patients need to be awaited.

\section{Concluding remarks}

The new Rotterdam criteria appeared to increase the heterogeneity of an already heterogeneous PCOS population. With the implementation of the Rotterdam criteria, physicians and women are further confused about the long-term consequences of PCOS. Such confusion might have only been an academic problem, if young women with PCOS, had not found numerous indications the Internet that their future health is at great risk.

However, do young lean women with oligomenorrhea and PCO carry the same risk for diabetes and cardiovascular disease as the premenopausal women with persisting hyperandrogenism in addition to their obesity? From the findings presented here, there was no deterioration in fibrinolytic activity and no increase in adipose tissue inflammatory markers in lean PCOS patients; thus, these women appeared to carry fewer risk factors for metabolic and cardiovascular disturbances. Whether this translates to decreased risk of type 2 diabetes and cardiovascular disease among lean women with PCOS could not be answered in this thesis, and remains to be proven in the future. It can be hypothesized that lean women with PCOS and without marked hyperandrogenism are more likely to recover from the PCOS with increasing age and their future health risks are different from other women with other PCOS phenotypes. However, to determine this, long-term studies of different PCOS phenotypes and the respective long-term risks are warranted. 


\section{General conclusions}

The prevalence of PCOS in Northern Sweden is similar to other Western countries, and is subsequently the most common endocrine disturbance among women of childbearing age.

Hyperandrogenism is more strongly associated with components of the metabolic syndrome than oligomenorrhea/amenorrhea.

With a few questions and limited biochemical analyses, it is possible to identify women with PCOS and concurrent metabolic disturbances.

Overweight women with PCOS have impaired fibrinolysis and among women with PCOS, decreased fibrinolytic activity is associated with increased free androgen levels.

Lean women with PCOS have normal fibrinolytic activity.

The gene expression pattern of inflammatory markers in abdominal superficial subcutaneous tissue is similar in overweight PCOS patients and overweight control subjects; whereas, lean PCOS patients display lower expression of adipose inflammatory markers.

Sibutramine combined with brief lifestyle interventions results in weight reduction in overweight and obese women with PCOS, but the usefulness of treatment is questioned by recent safety studies. 


\section{Populärvetenskaplig sammanfattning på svenska}

Polycystiskt ovarialsyndrom (PCOS) är den vanligaste endokrina rubbningen hos kvinnor i barnafödande åldrar. Enligt de diagnoskriterier som kom 2003 och som används av de flesta gynekologer ska kvinnan uppvisa minst två av följande tre kriterier: tecken till ägglossningsstörning, tecken till hyperandrogenism eller typisk ultraljudsbild. Det finns studier som visar ökad förekomst av insulinresistens, typ 2 diabetes och försämrade blodfetter hos kvinnor med PCOS jämfört med ålders- och viktmatchade kontroller men det är oklart om dessa risker även gäller för kvinnor som diagnostiserats enligt de nya kriterierna och om det även gäller för smala kvinnor med PCOS.

I mitt avhandlingsarbete har vi försökt bestämma förekomst av PCOS i norra Sverige. Vi finner att 4,8 \% av kvinnor under 40 år uppfyller PCOS kriterierna enligt äldre, ej ultraljudsbaserade, kriterier. Kvinnor med enbart tecken på ägglossningsstörning skilde sig inte ur metabol synvinkel från kvinnor utan något symtom alls. Den grupp som uppvisade PCOS diagnos hade högre BMI, högre blodtryck och rapporterade i högre utsträckning tidigare högt blodtryck under graviditet och graviditetsdiabetes jämfört med de andra grupperna.

Störningar i det fibrinolytiska systemet är en viktig del i uppkomsten av hjärtkärlssjukdomar och kan mätas med PAI-1 (plasminogen aktivator hämmare) och tPA (vävnads plasminogen aktivator). Vi har undersökt det fibrinolytiska systemet hos kvinnor med PCOS med ålders och viktmatchade kontroller. De smala PCOS kvinnorna skilde sig inte från smala kontroller med avseende på fibrinolytisk aktivitet oavsett hur man ställt PCOS diagnos. Bland överviktiga kvinnor med PCOS fann vid ökade nivåer av tPA massa oavsett om hyperandrogenism inkluderas i diagnosen eller ej. PAI-1 aktivitet var endast ökad bland kvinnor med PCOS som uppvisade hyperandrogenism.

Fettväven är kroppens allra största endokrina organ som producerar och frisläpper hormoner, proinflammatoriska och antiinflammatoriska cytokiner. Inflammation i fettväv är kopplat till insulinresistens och ökad risk för hjärtkärlsjukdom. Särskilt bukfetma är en känd riskfaktor för metabola störningar. Man har tidigare visat att markörer för inflammation är ökad i blod hos överviktiga PCOS kvinnor jämfört med viktmatchade kontroller men studier direkt på fettväv finns inte sedan tidigare. Vi har jämfört överviktiga och 
smala PCOS kvinnor med överviktiga friska kontroller och någon skillnad i genuttryck för inflammatoriska markörer mellan de två överviktiga grupperna sågs ej men de smala kvinnorna med PCOS hade lägre nivåer både jämfört med den överviktiga PCOS gruppen och den överviktiga kontrollgruppen.

Viktnedgång är förstahandsbehandling för överviktiga kvinnor med PCOS. Vi har provat om behandling med sibutramin, som är en serotonin/noradrenalin återupptagshämmare som verkar direkt på aptitcentrum $\mathrm{i}$ hjärnan, i kombination med livsstilsintervention kan leda till viktnedgång hos kvinnor med PCOS. Vi fann en signifikant bättre viktminskning med sibutramin och livsstilsintervention jämfört med placebo och livsstilsintervention. Vissa metabola parametrar förbättrades också med behandling men vi såg ingen förbättring i blodtryck trots viktminskningen. Sibutramin har dock nyligen blivit indraget då säkerhetsstudier visat på en ökad risk för kardiovaskulära komplikationer hos redan hjärtsjuka individer. 


\section{Acknowledgements}

This work was carried out at the Department of Women's and Children's Health, Uppsala University, Sweden. I would like to thank all those who helped, supported, and encouraged me during the work on this thesis

I wish to express my sincere gratitude to:

Inger Sundström-Poromaa, Professor at the Department of Women's and Children's Health, Uppsala University, my main supervisor who gave me the idea the work could be done. Thanks for all the food at the evening séances in your home, and to your family for putting up with all late visitors. Without YOU, this work would not been done at all.

Marie Bixo, Associate Professor at the Department of Clinical Science, Obstetric and Gynecology, Umeå University, my co-supervisor who taught me to concentrate on one thing at the time. Marie also provided me wonderful meals in Umeå.

Mats Eliasson, Associate Professor at the Department of Internal Medicine, Sunderby Hospital, Luleå, and the Department of Public Health and Clinical Medicine, Umeå University, Umeå, my second co-supervisor. He kept me updated on the mystery of clinical medicine and held my hand when Uppsala and Umeå was far away.

Ove Axelsson, Professor and Head of the Department of Women's and Children's health, Uppsala University, for giving me the opportunity to pursue my doctoral studies at Uppsala University.

Torbjörn Bäckström, Professor at the Department of Clinical Science, Obstetrics and Gynecology, Umeå University and Per-Åke Holmberg, Director of the clinical division of the Department of Obstetrics and Gynecology, Umeå University Hospital, who provided financial support for my work.

Gösta Granberg and Anna Pohjanen, past and present Directors of the Department of Obstetrics and Gynecology, Sunderby Hospital, Luleå: thanks for letting me have free time to do the work. 
Liselott Andersson, friend, colleague, and wine and food lover will have a special thank you for not breaking down when our working room in Luleå looked like a mess. Special thanks for statistical help and with the cover of this thesis, and for all the late nights without research.

Tommy Olsson, Professor at the Department of Public Health and Clinical Medicine, Umeå University, Umeå, who inspired me to enter the inflammatory world.

Jonas Buren and Caroline Blomqvist at the Department of Public Health and Clinical Medicine, Umeå University, Umeå, who helped me with PCR analyses of adipose tissue inflammatory markers and the writing of Paper III.

Owe Jonson, Associate Professor at the Department of Public Health and Clinical Medicine, Umeå University, who prompted me to go into the field of fibrinolysis.

Anders Larsson, Professor at the Department of Clinical Chemistry, Uppsala University, who helped with all the biochemistry analyses and suggested more to be done.

Inger Björn, Läkarhuset Björnen, Piteå, Sweden, for excellent recruitment of PCOS patients (and all CRFs in perfect order) and excellent co-writing of Paper IV.

Pål Wölner-Hanson, Department of Obstetrics and Gynecology, Lund University Hospital, for recruiting patients at the very beginning of my thesis and for co-writing Paper IV.

Tony Olsson and Ingrid Dahlbom, Department of Women's and Children's Health, Uppsala University, for analyses of peripheral inflammatory markers and for co-writing Paper III.

Lena Moby, Sigrid Nyberg, Gunnel Vidgren, Åsa Pettersson, and Ingrid Ottenbring, for keeping track of all the patients and their blood samples.

Special thanks to Alkistis Skalkidou and her father Yannis Skalkidou who had the courage to lend us their beautiful summerhouse in Kea, Greece, for one week of intense scientific work.

All researchers at the Department of Women's and Children's Health, Uppsala University who went to Kea in September 2009. I have never in my life met such enthusiasm for science and food: a lot of cooking talents sleeping there. 
All colleagues at the Department of Obstetrics and Gynecology, Sunderby Hospital, Luleå, for supporting my work.

Åsa Bäckström and Susanne Yttergren, friends in Umeå, Anna Lindholm sister-in-law in Uppsala, and Ninna Bromark friend in Uppsala for letting me into your house, sleeping, eating, and chatting, when I needed somewhere to stay during my work outside Luleå.

My family in Luleå who survived when I wasn't at home. Thanks to Thomas, my husband, for letting me do this, and a special thank to my mother who always believed in me.

Thank you to all women, who understood the research was important and were willing to participate in these studies. Without YOU, I wouldn't have been able to do this.

These studies were supported by the Family Planning Foundation, Selander Foundation, Visare i Norr, Nordsvenska Gynekologiska föreningen, Schering-Plough and FoU Norrbotten. 


\section{References/Bibliography}

1. Azziz R. PCOS: a diagnostic challenge. Reprod Biomed Online 2004;8:644-8.

2. Revised 2003 consensus on diagnostic criteria and long-term health risks related to polycystic ovary syndrome. Fertil Steril 2004;81:19-25.

3. Stein IF, Leventhal ML. Amenorrhoea associated with bilateral polycystic ovaries. Am J Obstet Gynecol 1935:29: 181-91.

4. Koivunen R, Laatikainen T, Tomas C, Huhtaniemi I, Tapanainen J, Martikainen $\mathrm{H}$. The prevalence of polycystic ovaries in healthy women. Acta Obstet Gynecol Scand 1999;78:137-41.

5. PCOS i tonåren. In: Polycystiskt ovarialsyndrom (PCOS). 1 ed; 2008:21.

6. Dokras A, Bochner M, Hollinrake E, Markham S, Vanvoorhis B, Jagasia DH. Screening women with polycystic ovary syndrome for metabolic syndrome. Obstet Gynecol 2005;106:131-7.

7. Legro RS, Kunselman AR, Dodson WC, Dunaif A. Prevalence and predictors of risk for type 2 diabetes mellitus and impaired glucose tolerance in polycystic ovary syndrome: a prospective, controlled study in 254 affected women. J Clin Endocrinol Metab 1999;84:165-9.

8. Ehrmann DA, Barnes RB, Rosenfield RL, Cavaghan MK, Imperial J. Prevalence of impaired glucose tolerance and diabetes in women with polycystic ovary syndrome. Diabetes Care 1999;22:141-6.

9. 9.Holte J, Bergh T, Berne C, Lithell H. Serum lipoprotein lipid profile in women with the polycystic ovary syndrome: relation to anthropometric, endocrine and metabolic variables. Clin Endocrinol (Oxf) 1994;41:463-71.

10. Robinson S, Henderson AD, Gelding SV, Kiddy D, Niththyananthan R, Bush A, Richmond W, Johnston DG, Franks S. Dyslipidaemia is associated with insulin resistance in women with polycystic ovaries. Clin Endocrinol (Oxf) 1996;44:277-84.

11. Wild RA, Painter PC, Coulson PB, Carruth KB, Ranney GB. Lipoprotein lipid concentrations and cardiovascular risk in women with polycystic ovary syndrome. J Clin Endocrinol Metab 1985;61:946-51.

12. Dahlgren E, Janson PO, Johansson S, Lapidus L, Oden A. Polycystic ovary syndrome and risk for myocardial infarction. Evaluated from a risk factor model based on a prospective population study of women. Acta Obstet Gynecol Scand 1992;71:599-604.

13. Lakhani K, Seifalian AM, Hardiman P. Impaired carotid viscoelastic properties in women with polycystic ovaries. Circulation 2002;106:81-5. 
14. Atiomo WU, Bates SA, Condon JE, Shaw S, West JH, Prentice AG. The plasminogen activator system in women with polycystic ovary syndrome. Fertil Steril 1998;69:236-41.

15. Sampson M, Kong C, Patel A, Unwin R, Jacobs HS. Ambulatory blood pressure profiles and plasminogen activator inhibitor (PAI-1) activity in lean women with and without the polycystic ovary syndrome. Clin Endocrinol (Oxf) 1996;45:623-9.

16. Zawadski JK. Diagnostic criteria for polycystic ovary syndrome; towards a rational approach. In: Dunaif A GJ, Hasseltine F, ed. Polycystic ovary syndrome. Boston: Blacwell scintific; 1992:377-84.

17. Welt CK, Gudmundsson JA, Arason G, Adams J, Palsdottir H, Gudlaugsdottir G, Ingadottir G, Crowley WF. Characterizing discrete subsets of polycystic ovary syndrome as defined by the Rotterdam criteria: the impact of weight on phenotype and metabolic features. J Clin Endocrinol Metab 2006;91:4842-8.

18. Azziz R, Carmina E, Dewailly D, Diamanti-Kandarakis E, EscobarMorreale HF, Futterweit W, Janssen OE, Legro RS, Norman RJ, Taylor AE, Witchel SF. Positions statement: criteria for defining polycystic ovary syndrome as a predominantly hyperandrogenic syndrome: an Androgen Excess Society guideline. J Clin Endocrinol Metab 2006;91:4237-45.

19. Carmina E, Napoli N, Longo RA, Rini GB, Lobo RA. Metabolic syndrome in polycystic ovary syndrome (PCOS): lower prevalence in southern Italy than in the USA and the influence of criteria for the diagnosis of PCOS. Eur J Endocrinol 2006;154:141-5.

20. Carmina E, Rosato F, Janni A, Rizzo M, Longo RA. Extensive clinical experience: relative prevalence of different androgen excess disorders in 950 women referred because of clinical hyperandrogenism. J Clin Endocrinol Metab 2006;91:2-6.

21. Apridonidze T, Essah PA, Iuorno MJ, Nestler JE. Prevalence and characteristics of the metabolic syndrome in women with polycystic ovary syndrome. J Clin Endocrinol Metab 2005;90:1929-35.

22. Chen MJ, Yang WS, Yang JH, Chen CL, Ho HN, Yang YS. Relationship between androgen levels and blood pressure in young women with polycystic ovary syndrome. Hypertension 2007;49:1442-7.

23. Volgsten H, Skoog Svanberg A, Ekselius L, Lundkvist O, Sundstrom Poromaa I. Prevalence of psychiatric disorders in infertile women and men undergoing in vitro fertilization treatment. Hum Reprod 2008;23:2056-63.

24. Barnard L, Ferriday D, Guenther N, Strauss B, Balen AH, Dye L. Quality of life and psychological well being in polycystic ovary syndrome. Hum Reprod 2007;22:2279-86.

25. Weiner CL, Primeau M, Ehrmann DA. Androgens and mood dysfunction in women: comparison of women with polycystic ovarian syndrome to healthy controls. Psychosom Med 2004;66:356-62. 
26. Elsenbruch S, Hahn S, Kowalsky D, Offner AH, Schedlowski M, Mann K, Janssen OE. Quality of life, psychosocial well-being, and sexual satisfaction in women with polycystic ovary syndrome. J Clin Endocrinol Metab 2003;88:5801-7.

27. Hollinrake E, Abreu A, Maifeld M, Van Voorhis BJ, Dokras A. Increased risk of depressive disorders in women with polycystic ovary syndrome. Fertil Steril 2007;87:1369-76.

28. Jedel E, Waern M, Gustafson D, Landen M, Eriksson E, Holm G, Nilsson L, Lind AK, Janson PO, Stener-Victorin E. Anxiety and depression symptoms in women with polycystic ovary syndrome compared with controls matched for body mass index. Hum Reprod;25:450-6.

29. Mansson M, Holte J, Landin-Wilhelmsen K, Dahlgren E, Johansson A, Landen M. Women with polycystic ovary syndrome are often depressed or anxious--a case control study. Psychoneuroendocrinology 2008;33:1132-8.

30. Diamanti-Kandarakis E, Kouli CR, Bergiele AT, Filandra FA, Tsianateli TC, Spina GG, Zapanti ED, Bartzis MI. A survey of the polycystic ovary syndrome in the Greek island of Lesbos: hormonal and metabolic profile. J Clin Endocrinol Metab 1999;84:4006-11.

31. Azziz R, Woods KS, Reyna R, Key TJ, Knochenhauer ES, Yildiz BO. The prevalence and features of the polycystic ovary syndrome in an unselected population. J Clin Endocrinol Metab 2004;89:2745-9.

32. Asuncion M, Calvo RM, San Millan JL, Sancho J, Avila S, EscobarMorreale HF. A prospective study of the prevalence of the polycystic ovary syndrome in unselected Caucasian women from Spain. J Clin Endocrinol Metab 2000;85:2434-8.

33. Taponen S, Martikainen H, Jarvelin MR, Laitinen J, Pouta A, Hartikainen AL, Sovio U, McCarthy MI, Franks S, Ruokonen A. Hormonal profile of women with self-reported symptoms of oligomenorrhea and/or hirsutism: Northern Finland birth cohort 1966 study. J Clin Endocrinol Metab 2003;88:141-7.

34. Mathur RS, Moody LO, Landgrebe S, Williamson HO. Plasma androgens and sex hormone-binding globulin in the evaluation of hirsute females. Fertil Steril 1981;35:29-35.

35. Manni A, Pardridge WM, Cefalu W, Nisula BC, Bardin CW, Santner SJ, Santen RJ. Bioavailability of albumin-bound testosterone. J Clin Endocrinol Metab 1985;61:705-10.

36. Miller KK, Rosner W, Lee H, Hier J, Sesmilo G, Schoenfeld D, Neubauer $\mathrm{G}$, Klibanski A. Measurement of free testosterone in normal women and women with androgen deficiency: comparison of methods. J Clin Endocrinol Metab 2004;89:525-33.

37. Vermeulen A, Verdonck L, Kaufman JM. A critical evaluation of simple methods for the estimation of free testosterone in serum. J Clin Endocrinol Metab 1999;84:3666-72. 
38. Diagnoskriterier och utredning av PCOS. In: Polycystiskt ovarialsyndrom (PCOS). 1 ed: SFOG; 2008:12.

39. Fehring RJ, Schneider M, Raviele K. Variability in the phases of the menstrual cycle. J Obstet Gynecol Neonatal Nurs 2006;35:376-84.

40. March WA, Moore VM, Willson KJ, Phillips DI, Norman RJ, Davies MJ. The prevalence of polycystic ovary syndrome in a community sample assessed under contrasting diagnostic criteria. Hum Reprod;25:544-51.

41. Cresswell JL, Barker DJ, Osmond C, Egger P, Phillips DI, Fraser RB. Fetal growth, length of gestation, and polycystic ovaries in adult life. Lancet 1997;350:1131-5.

42. Kahsar-Miller MD, Nixon C, Boots LR, Go RC, Azziz R. Prevalence of polycystic ovary syndrome (PCOS) in first-degree relatives of patients with PCOS. Fertil Steril 2001;75:53-8.

43. Yildiz BO, Yarali H, Oguz H, Bayraktar M. Glucose intolerance, insulin resistance, and hyperandrogenemia in first degree relatives of women with polycystic ovary syndrome. J Clin Endocrinol Metab 2003;88:2031-6.

44. Cheang KI, Nestler JE, Futterweit W. Risk of cardiovascular events in mothers of women with polycystic ovary syndrome. Endocr Pract 2008;14:1084-94.

45. Battaglia C, Mancini F, Cianciosi A, Busacchi P, Persico N, Paradisi R, Facchinetti F, de Aloysio D. Cardiovascular risk in normal weight, eumenorrheic, nonhirsute daughters of patients with polycystic ovary syndrome: a pilot study. Fertil Steril 2009;92:240-9.

46. Urbanek M, Sam S, Legro RS, Dunaif A. Identification of a polycystic ovary syndrome susceptibility variant in fibrillin-3 and association with a metabolic phenotype. J Clin Endocrinol Metab 2007;92:4191-8.

47. Sam S, Coviello AD, Sung YA, Legro RS, Dunaif A. Metabolic phenotype in the brothers of women with polycystic ovary syndrome. Diabetes Care 2008;31:1237-41.

48. Coviello AD, Sam S, Legro RS, Dunaif A. High prevalence of metabolic syndrome in first-degree male relatives of women with polycystic ovary syndrome is related to high rates of obesity. J Clin Endocrinol Metab 2009;94:4361-6.

49. Escobar-Morreale HF, San Millan JL. Abdominal adiposity and the polycystic ovary syndrome. Trends Endocrinol Metab 2007;18:266-72.

50. Elbers JM, Giltay EJ, Teerlink T, Scheffer PG, Asscheman H, Seidell JC, Gooren LJ. Effects of sex steroids on components of the insulin resistance syndrome in transsexual subjects. Clin Endocrinol (Oxf) 2003;58:562-71.

51. Alexanderson C, Eriksson E, Stener-Victorin E, Lystig T, Gabrielsson B, Lonn M, Holmang A. Postnatal testosterone exposure results in insulin resistance, enlarged mesenteric adipocytes, and an atherogenic lipid profile in adult female rats: comparisons with estradiol and dihydrotestosterone. Endocrinology 2007;148:5369-76. 
52. Franks S. Adult polycystic ovary syndrome begins in childhood. Best Pract Res Clin Endocrinol Metab 2002;16:263-72.

53. Xita N, Tsatsoulis A. Review: fetal programming of polycystic ovary syndrome by androgen excess: evidence from experimental, clinical, and genetic association studies. J Clin Endocrinol Metab 2006;91:1660-6.

54. Gambineri A, Pelusi C, Vicennati V, Pagotto U, Pasquali R. Obesity and the polycystic ovary syndrome. Int $\mathrm{J}$ Obes Relat Metab Disord 2002;26:883-96.

55. Alberti KG, Eckel RH, Grundy SM, Zimmet PZ, Cleeman JI, Donato KA, Fruchart JC, James WP, Loria CM, Smith SC, Jr. Harmonizing the metabolic syndrome: a joint interim statement of the International Diabetes Federation Task Force on Epidemiology and Prevention; National Heart, Lung, and Blood Institute; American Heart Association; World Heart Federation; International Atherosclerosis Society; and International Association for the Study of Obesity. Circulation 2009;120:1640-5.

56. Dahlgren E, Johansson S, Lindstedt G, Knutsson F, Oden A, Janson PO, Mattson LA, Crona N, Lundberg PA. Women with polycystic ovary syndrome wedge resected in 1956 to 1965: a long-term follow-up focusing on natural history and circulating hormones. Fertil Steril 1992;57:505-13.

57. Dunaif A. Drug insight: insulin-sensitizing drugs in the treatment of polycystic ovary syndrome--a reappraisal. Nat Clin Pract Endocrinol Metab 2008;4:272-83.

58. Ehrmann DA, Liljenquist DR, Kasza K, Azziz R, Legro RS, Ghazzi MN. Prevalence and predictors of the metabolic syndrome in women with polycystic ovary syndrome. J Clin Endocrinol Metab 2006;91:48-53.

59. Moran L, Teede H. Metabolic features of the reproductive phenotypes of polycystic ovary syndrome. Hum Reprod Update 2009;15:477-88.

60. Burghen GA, Givens JR, Kitabchi AE. Correlation of hyperandrogenism with hyperinsulinism in polycystic ovarian disease. J Clin Endocrinol Metab 1980;50:113-6.

61. Svendsen PF, Nilas L, Madsbad S, Holst JJ. Incretin hormone secretion in women with polycystic ovary syndrome: roles of obesity, insulin sensitivity, and treatment with metformin. Metabolism 2009;58:586-93.

62. Toprak S, Yonem A, Cakir B, Guler S, Azal O, Ozata M, Corakci A. Insulin resistance in nonobese patients with polycystic ovary syndrome. Horm Res 2001;55:65-70.

63. Yucel A, Noyan V, Sagsoz N. The association of serum androgens and insulin resistance with fat distribution in polycystic ovary syndrome. Eur J Obstet Gynecol Reprod Biol 2006;126:81-6.

64. Dunaif A. Insulin resistance and the polycystic ovary syndrome: mechanism and implications for pathogenesis. Endocr Rev 1997;18:774-800.

65. Gennarelli G, Holte J, Berglund L, Berne C, Massobrio M, Lithell H. Prediction models for insulin resistance in the polycystic ovary syndrome. Hum Reprod 2000;15:2098-102. 
66. Diamanti-Kandarakis E, Mitrakou A, Hennes MM, Platanissiotis D, Kaklas N, Spina J, Georgiadou E, Hoffmann RG, Kissebah AH, Raptis S. Insulin sensitivity and antiandrogenic therapy in women with polycystic ovary syndrome. Metabolism 1995;44:525-31.

67. Dunaif A, Segal KR, Futterweit W, Dobrjansky A. Profound peripheral insulin resistance, independent of obesity, in polycystic ovary syndrome. Diabetes 1989;38:1165-74.

68. Kowalska I, Straczkowski M, Nikolajuk A, Adamska A, KarczewskaKupczewska M, Otziomek E, Wolczynski S, Gorska M. Serum visfatin in relation to insulin resistance and markers of hyperandrogenism in lean and obese women with polycystic ovary syndrome. Hum Reprod 2007;22:18249.

69. Tosi F, Dorizzi R, Castello R, Maffeis C, Spiazzi G, Zoppini G, Muggeo $\mathrm{M}$, Moghetti P. Body fat and insulin resistance independently predict increased serum C-reactive protein in hyperandrogenic women with polycystic ovary syndrome. Eur J Endocrinol 2009;161:737-45.

70. Baillargeon JP, Carpentier A. Role of insulin in the hyperandrogenemia of lean women with polycystic ovary syndrome and normal insulin sensitivity. Fertil Steril 2007;88:886-93.

71. Holte J, Bergh T, Berne C, Wide L, Lithell H. Restored insulin sensitivity but persistently increased early insulin secretion after weight loss in obese women with polycystic ovary syndrome. J Clin Endocrinol Metab 1995;80:2586-93.

72. Morin-Papunen LC, Vauhkonen I, Koivunen RM, Ruokonen A, Tapanainen JS. Insulin sensitivity, insulin secretion, and metabolic and hormonal parameters in healthy women and women with polycystic ovarian syndrome. Hum Reprod 2000;15:1266-74.

73. Vrbikova J, Cibula D, Dvorakova K, Stanicka S, Sindelka G, Hill M, Fanta M, Vondra K, Skrha J. Insulin sensitivity in women with polycystic ovary syndrome. J Clin Endocrinol Metab 2004;89:2942-5.

74. Barber TM, Wass JA, McCarthy MI, Franks S. Metabolic characteristics of women with polycystic ovaries and oligo-amenorrhoea but normal androgen levels: implications for the management of polycystic ovary syndrome. Clin Endocrinol (Oxf) 2007;66:513-7.

75. Belosi C, Selvaggi L, Apa R, Guido M, Romualdi D, Fulghesu AM, Lanzone A. Is the PCOS diagnosis solved by ESHRE/ASRM 2003 consensus or could it include ultrasound examination of the ovarian stroma? Hum Reprod 2006;21:3108-15.

76. Lakhani K, Constantinovici N, Purcell WM, Fernando R, Hardiman P. Internal carotid-artery response to $5 \%$ carbon dioxide in women with polycystic ovaries. Lancet 2000;356:1166-7.

77. Lakhani K, Constantinovici N, Purcell WM, Fernando R, Hardiman P. Internal carotid artery haemodynamics in women with polycystic ovaries. Clin Sci (Lond) 2000;98:661-5. 
78. Macut D, Micic D, Cvijovic G, Sumarac M, Kendereski A, Zoric S, Pejkovic D. Cardiovascular risk in adolescent and young adult obese females with polycystic ovary syndrome (PCOS). J Pediatr Endocrinol Metab 2001;14 Suppl 5:1353-59; discussion 65.

79. Diamanti-Kandarakis E, Paterakis T, Alexandraki K, Piperi C, Aessopos A, Katsikis I, Katsilambros N, Kreatsas G, Panidis D. Indices of low-grade chronic inflammation in polycystic ovary syndrome and the beneficial effect of metformin. Hum Reprod 2006;21:1426-31.

80. Glintborg D, Andersen M, Richelsen B, Bruun JM. Plasma monocyte chemoattractant protein-1 and macrophage inflammatory protein-1alpha are increased in patients with polycystic ovary syndrome and associated with adiposity, but unaffected by pioglitazone treatment. Clin Endocrinol (Oxf) 2009.

81. Gonzalez F, Rote NS, Minium J, Kirwan JP. Evidence of proatherogenic inflammation in polycystic ovary syndrome. Metabolism 2009;58:954-62.

82. Holte J, Gennarelli G, Berne C, Bergh T, Lithell H. Elevated ambulatory day-time blood pressure in women with polycystic ovary syndrome: a sign of a pre-hypertensive state? Hum Reprod 1996;11:23-8.

83. Brinkworth GD, Noakes M, Moran LJ, Norman R, Clifton PM. Flowmediated dilatation in overweight and obese women with polycystic ovary syndrome. BJOG 2006;113:1308-14.

84. Mather KJ, Verma S, Corenblum B, Anderson TJ. Normal endothelial function despite insulin resistance in healthy women with the polycystic ovary syndrome. J Clin Endocrinol Metab 2000;85:1851-6.

85. Kravariti M, Naka KK, Kalantaridou SN, Kazakos N, Katsouras CS, Makrigiannakis A, Paraskevaidis EA, Chrousos GP, Tsatsoulis A, Michalis LK. Predictors of endothelial dysfunction in young women with polycystic ovary syndrome. J Clin Endocrinol Metab 2005;90:5088-95.

86. Orio F, Jr., Palomba S, Cascella T, De Simone B, Di Biase S, Russo T, Labella D, Zullo F, Lombardi G, Colao A. Early impairment of endothelial structure and function in young normal-weight women with polycystic ovary syndrome. J Clin Endocrinol Metab 2004;89:4588-93.

87. Tarkun I, Arslan BC, Canturk Z, Turemen E, Sahin T, Duman C. Endothelial dysfunction in young women with polycystic ovary syndrome: relationship with insulin resistance and low-grade chronic inflammation. J Clin Endocrinol Metab 2004;89:5592-6.

88. Moran LJ, Hutchison SK, Meyer C, Zoungas S, Teede HJ. A comprehensive assessment of endothelial function in overweight women with and without polycystic ovary syndrome. Clin Sci (Lond) 2009;116:761-70.

89. Meyer C, McGrath BP, Teede HJ. Overweight women with polycystic ovary syndrome have evidence of subclinical cardiovascular disease. J Clin Endocrinol Metab 2005;90:5711-6.

90. Vryonidou A, Papatheodorou A, Tavridou A, Terzi T, Loi V, Vatalas IA, Batakis N, Phenekos C, Dionyssiou-Asteriou A. Association of hyperan- 
drogenemic and metabolic phenotype with carotid intima-media thickness in young women with polycystic ovary syndrome. J Clin Endocrinol Metab 2005;90:2740-6.

91. Talbott EO, Zborowski JV, Boudreaux MY, McHugh-Pemu KP, SuttonTyrrell K, Guzick DS. The relationship between C-reactive protein and carotid intima-media wall thickness in middle-aged women with polycystic ovary syndrome. J Clin Endocrinol Metab 2004;89:6061-7.

92. Carmina E, Orio F, Palomba S, Longo RA, Cascella T, Colao A, Lombardi G, Rini GB, Lobo RA. Endothelial dysfunction in PCOS: role of obesity and adipose hormones. Am J Med 2006;119:356 e1-6.

93. Cibula D, Cifkova R, Fanta M, Poledne R, Zivny J, Skibova J. Increased risk of non-insulin dependent diabetes mellitus, arterial hypertension and coronary artery disease in perimenopausal women with a history of the polycystic ovary syndrome. Hum Reprod 2000;15:785-9.

94. Wild S, Pierpoint T, McKeigue P, Jacobs H. Cardiovascular disease in women with polycystic ovary syndrome at long-term follow-up: a retrospective cohort study. Clin Endocrinol (Oxf) 2000;52:595-600.

95. Pierpoint T, McKeigue PM, Isaacs AJ, Wild SH, Jacobs HS. Mortality of women with polycystic ovary syndrome at long-term follow-up. J Clin Epidemiol 1998;51:581-6.

96. Shaw LJ, Bairey Merz CN, Azziz R, Stanczyk FZ, Sopko G, Braunstein GD, Kelsey SF, Kip KE, Cooper-Dehoff RM, Johnson BD, Vaccarino V, Reis SE, Bittner V, Hodgson TK, Rogers W, Pepine CJ. Postmenopausal women with a history of irregular menses and elevated androgen measurements at high risk for worsening cardiovascular event-free survival: results from the National Institutes of Health--National Heart, Lung, and Blood Institute sponsored Women's Ischemia Syndrome Evaluation. J Clin Endocrinol Metab 2008;93:1276-84.

97. Nilsson T WP. The fibrinolytic system: biochemistry and assay methods. In: Nilsson T BK, Jansson J, ed. Clinical aspects of fibrinolysis: Almqvist \& Wiksell; 1991:9-54.

98. Jansson JH, Nilsson TK, Johnson O. von Willebrand factor, tissue plasminogen activator, and dehydroepiandrosterone sulphate predict cardiovascular death in a 10 year follow up of survivors of acute myocardial infarction. Heart 1998;80:334-7.

99. Mannucci PM, Bernardinelli L, Foco L, Galli M, Ribichini F, Tubaro M, Peyvandi F. Tissue plasminogen activator antigen is strongly associated with myocardial infarction in young women. $\mathrm{J}$ Thromb Haemost 2005;3:280-6.

100. Orio F, Jr., Palomba S, Cascella T, Tauchmanova L, Nardo LG, Di Biase S, Labella D, Russo T, Savastano S, Tolino A, Zullo F, Colao A, Lombardi G. Is plasminogen activator inhibitor-1 a cardiovascular risk factor in young women with polycystic ovary syndrome? Reprod Biomed Online 2004;9:505-10. 
101. Tarkun I, Canturk Z, Arslan BC, Turemen E, Tarkun P. The plasminogen activator system in young and lean women with polycystic ovary syndrome. Endocr J 2004;51:467-72.

102. Atiomo WU, Fox R, Condon JE, Shaw S, Friend J, Prentice AG, Wilkin TJ. Raised plasminogen activator inhibitor-1 (PAI-1) is not an independent risk factor in the polycystic ovary syndrome (PCOS). Clin Endocrinol (Oxf) 2000;52:487-92.

103.Slopien R, Lewandowski K, Kolacz E, Zawilska K, WarenikSzymankiewicz A. Comparison of fibrinolytic and metabolic system parameters in obese patients with polycystic ovary syndrome and women with simple obesity. Gynecol Endocrinol 2006;22:651-4.

104. Kelly CJ, Lyall H, Petrie JR, Gould GW, Connell JM, Rumley A, Lowe GD, Sattar N. A specific elevation in tissue plasminogen activator antigen in women with polycystic ovarian syndrome. J Clin Endocrinol Metab 2002;87:3287-90.

105.Lin S, Yongmei G. Plasminogen activator and plasma activator inhibitor-1 in young women with polycystic ovary syndrome. Int J Gynaecol Obstet 2008;100:285-6.

106.Sills ES, Drews CD, Perloe M, Tucker MJ, Kaplan CR, Palermo GD. Absence of profound hyperinsulinism in polycystic ovary syndrome is associated with subtle elevations in the plasminogen activator inhibitor system. Gynecol Endocrinol 2003;17:231-7.

107.Carmassi F, De Negri F, Fioriti R, De Giorgi A, Giannarelli C, Fruzzetti F, Pedrinelli R, Dell'Omo G, Bersi C. Insulin resistance causes impaired vasodilation and hypofibrinolysis in young women with polycystic ovary syndrome. Thromb Res 2005;116:207-14.

108. Knochenhauer ES, Key TJ, Kahsar-Miller M, Waggoner W, Boots LR, Azziz R. Prevalence of the polycystic ovary syndrome in unselected black and white women of the southeastern United States: a prospective study. J Clin Endocrinol Metab 1998;83:3078-82.

109.Alvarez-Blasco F, Botella-Carretero JI, San Millan JL, Escobar-Morreale HF. Prevalence and characteristics of the polycystic ovary syndrome in overweight and obese women. Arch Intern Med 2006;166:2081-6.

110. Hirschberg AL. Polycystic ovary syndrome, obesity and reproductive implications. Womens Health (Lond Engl) 2009;5:529-40; quiz 41-2.

111.Hirschberg AL, Naessen S, Stridsberg M, Bystrom B, Holtet J. Impaired cholecystokinin secretion and disturbed appetite regulation in women with polycystic ovary syndrome. Gynecol Endocrinol 2004;19:79-87.

112.Pagotto U, Gambineri A, Vicennati V, Heiman ML, Tschop M, Pasquali R. Plasma ghrelin, obesity, and the polycystic ovary syndrome: correlation with insulin resistance and androgen levels. J Clin Endocrinol Metab 2002;87:5625-9.

113.Kim S, Moustaid-Moussa N. Secretory, endocrine and autocrine/paracrine function of the adipocyte. J Nutr 2000;130:3110S-5S. 
114. Mahadik SR, Deo SS, Mehtalia SD. Association of adiposity, inflammation and atherosclerosis: the role of adipocytokines and CRP in Asian Indian subjects. Metab Syndr Relat Disord 2008;6:121-8.

115.Despres JP, Lemieux I. Abdominal obesity and metabolic syndrome. Nature 2006;444:881-7.

116.Cancello R, Clement K. Is obesity an inflammatory illness? Role of lowgrade inflammation and macrophage infiltration in human white adipose tissue. BJOG 2006;113:1141-7.

117.Kershaw EE, Flier JS. Adipose tissue as an endocrine organ. J Clin Endocrinol Metab 2004;89:2548-56.

118. Bruun JM, Stallknecht B, Helge JW, Richelsen B. Interleukin-18 in plasma and adipose tissue: effects of obesity, insulin resistance, and weight loss. Eur J Endocrinol 2007;157:465-71.

119.Skopkova M, Penesova A, Sell H, Radikova Z, Vlcek M, Imrich R, Koska J, Ukropec J, Eckel J, Klimes I, Gasperikova D. Protein array reveals differentially expressed proteins in subcutaneous adipose tissue in obesity. Obesity (Silver Spring) 2007;15:2396-406.

120. Hotamisligil GS, Arner P, Caro JF, Atkinson RL, Spiegelman BM. Increased adipose tissue expression of tumor necrosis factor-alpha in human obesity and insulin resistance. J Clin Invest 1995;95:2409-15.

121. Hotamisligil GS. Inflammation and metabolic disorders. Nature 2006;444:860-7.

122. Moran LJ, Noakes M, Clifton PM, Tomlinson L, Galletly C, Norman RJ. Dietary composition in restoring reproductive and metabolic physiology in overweight women with polycystic ovary syndrome. J Clin Endocrinol Metab 2003;88:812-9.

123. Thomson RL, Buckley JD, Moran LJ, Noakes M, Clifton PM, Norman RJ, Brinkworth GD. The effect of weight loss on anti-Mullerian hormone levels in overweight and obese women with polycystic ovary syndrome and reproductive impairment. Hum Reprod 2009;24:1976-81.

124.Huber-Buchholz MM, Carey DG, Norman RJ. Restoration of reproductive potential by lifestyle modification in obese polycystic ovary syndrome: role of insulin sensitivity and luteinizing hormone. J Clin Endocrinol Metab 1999;84:1470-4.

125.Crosignani PG, Colombo M, Vegetti W, Somigliana E, Gessati A, Ragni G. Overweight and obese anovulatory patients with polycystic ovaries: parallel improvements in anthropometric indices, ovarian physiology and fertility rate induced by diet. Hum Reprod 2003;18:1928-32.

126. Thomas DE, Elliott EJ, Baur L. Low glycaemic index or low glycaemic load diets for overweight and obesity. Cochrane Database Syst Rev 2007:CD005105.

127.Palomba S, Giallauria F, Falbo A, Russo T, Oppedisano R, Tolino A, Colao A, Vigorito C, Zullo F, Orio F. Structured exercise training programme versus hypocaloric hyperproteic diet in obese polycystic ovary syndrome 
patients with anovulatory infertility: a 24-week pilot study. Hum Reprod 2008;23:642-50.

128. Thomson RL, Buckley JD, Noakes M, Clifton PM, Norman RJ, Brinkworth GD. The effect of a hypocaloric diet with and without exercise training on body composition, cardiometabolic risk profile, and reproductive function in overweight and obese women with polycystic ovary syndrome. J Clin Endocrinol Metab 2008;93:3373-80.

129.Lord JM, Flight IH, Norman RJ. Insulin-sensitising drugs (metformin, troglitazone, rosiglitazone, pioglitazone, D-chiro-inositol) for polycystic ovary syndrome. Cochrane Database Syst Rev 2003:CD003053.

130.Lord J, Thomas R, Fox B, Acharya U, Wilkin T. The effect of metformin on fat distribution and the metabolic syndrome in women with polycystic ovary syndrome--a randomised, double-blind, placebo-controlled trial. BJOG 2006;113:817-24.

131.Tang T, Glanville J, Hayden CJ, White D, Barth JH, Balen AH. Combined lifestyle modification and metformin in obese patients with polycystic ovary syndrome. A randomized, placebo-controlled, double-blind multicentre study. Hum Reprod 2006;21:80-9.

132. Heck AM, Yanovski JA, Calis KA. Orlistat, a new lipase inhibitor for the management of obesity. Pharmacotherapy 2000;20:270-9.

133. Harp JB. Orlistat for the long-term treatment of obesity. Drugs Today (Barc) 1999;35:139-45.

134. Rossner S, Sjostrom L, Noack R, Meinders AE, Noseda G. Weight loss, weight maintenance, and improved cardiovascular risk factors after 2 years treatment with orlistat for obesity. European Orlistat Obesity Study Group. Obes Res 2000;8:49-61.

135.Luque CA, Rey JA. Sibutramine: a serotonin-norepinephrine reuptakeinhibitor for the treatment of obesity. Ann Pharmacother 1999;33:968-78.

136. Berkowitz RI, Fujioka K, Daniels SR, Hoppin AG, Owen S, Perry AC, Sothern MS, Renz CL, Pirner MA, Walch JK, Jasinsky O, Hewkin AC, Blakesley VA. Effects of sibutramine treatment in obese adolescents: a randomized trial. Ann Intern Med 2006;145:81-90.

137.Redmon JB, Reck KP, Raatz SK, Swanson JE, Kwong CA, Ji H, Thomas W, Bantle JP. Two-year outcome of a combination of weight loss therapies for type 2 diabetes. Diabetes Care 2005;28:1311-5.

138. Wadden TA, Berkowitz RI, Womble LG, Sarwer DB, Phelan S, Cato RK, Hesson LA, Osei SY, Kaplan R, Stunkard AJ. Randomized trial of lifestyle modification and pharmacotherapy for obesity. $N$ Engl $\mathrm{J}$ Med 2005;353:2111-20.

139. Mathus-Vliegen EM. Long-term maintenance of weight loss with sibutramine in a GP setting following a specialist guided very-low-calorie diet: a double-blind, placebo-controlled, parallel group study. Eur J Clin Nutr 2005;59 Suppl 1:S31-8; discussion S9. 
140.Avenell A, Brown TJ, McGee MA, Campbell MK, Grant AM, Broom J, Jung RT, Smith WC. What interventions should we add to weight reducing diets in adults with obesity? A systematic review of randomized controlled trials of adding drug therapy, exercise, behaviour therapy or combinations of these interventions. J Hum Nutr Diet 2004;17:293-316.

141.Lazurova I, Dravecka I, Kraus V, Petrovicova J. Metformin versus sibutramine in the treatment of hyperinsulinemia in chronically anovulating women. Bratisl Lek Listy 2004;105:207-10.

142.Sabuncu T, Harma M, Nazligul Y, Kilic F. Sibutramine has a positive effect on clinical and metabolic parameters in obese patients with polycystic ovary syndrome. Fertil Steril 2003;80:1199-204.

143. Ashley JM, St Jeor ST, Schrage JP, Perumean-Chaney SE, Gilbertson MC, McCall NL, Bovee V. Weight control in the physician's office. Arch Intern Med 2001;161:1599-604.

144. Questions and answers on the suspension of medicines containing sibutramine. Outcome of a procedure under Article 107 of Directive 2001/83/EC. In: EMEA/H/A-107/1256; 2010.

145.Stegmayr B, Lundberg V, Asplund K. The events registration and survey procedures in the Northern Sweden MONICA Project. Scand J Public Health Suppl 2003;61:9-17.

146. Albareda M, Rodriguez-Espinosa J, Murugo M, de Leiva A, Corcoy R. Assessment of insulin sensitivity and beta-cell function from measurements in the fasting state and during an oral glucose tolerance test. Diabetologia 2000;43:1507-11.

147. Andersen CL, Jensen JL, Orntoft TF. Normalization of real-time quantitative reverse transcription-PCR data: a model-based variance estimation approach to identify genes suited for normalization, applied to bladder and colon cancer data sets. Cancer Res 2004;64:5245-50.

148. Taponen S, Ahonkallio S, Martikainen H, Koivunen R, Ruokonen A, Sovio U, Hartikainen AL, Pouta A, Laitinen J, King V, Franks S, McCarthy MI, Jarvelin MR. Prevalence of polycystic ovaries in women with self-reported symptoms of oligomenorrhoea and/or hirsutism: Northern Finland Birth Cohort 1966 Study. Hum Reprod 2004;19:1083-8.

149. Chen X, Yang D, Mo Y, Li L, Chen Y, Huang Y. Prevalence of polycystic ovary syndrome in unselected women from southern China. Eur J Obstet Gynecol Reprod Biol 2008;139:59-64.

150.Kumarapeli V, Seneviratne Rde A, Wijeyaratne CN, Yapa RM, Dodampahala SH. A simple screening approach for assessing community prevalence and phenotype of polycystic ovary syndrome in a semi-urban population in Sri Lanka. Am J Epidemiol 2008;168:321-8.

151.Pugeat M, Moulin P, Cousin P, Fimbel S, Nicolas MH, Crave JC, Lejeune $\mathrm{H}$. Interrelations between sex hormone-binding globulin (SHBG), plasma lipoproteins and cardiovascular risk. J Steroid Biochem Mol Biol 1995;53:567-72. 
152.Lambrinoudaki I, Christodoulakos G, Rizos D, Economou E, Argeitis J, Vlachou S, Creatsa M, Kouskouni E, Botsis D. Endogenous sex hormones and risk factors for atherosclerosis in healthy Greek postmenopausal women. Eur J Endocrinol 2006;154:907-16.

153.Haffner SM, Katz MS, Stern MP, Dunn JF. Association of decreased sex hormone binding globulin and cardiovascular risk factors. Arteriosclerosis 1989;9:136-43.

154.Haffner SM, Newcomb PA, Marcus PM, Klein BE, Klein R. Relation of sex hormones and dehydroepiandrosterone sulfate (DHEA-SO4) to cardiovascular risk factors in postmenopausal women. Am J Epidemiol 1995;142:925-34.

155. Sowers M, Crawford SL, Cauley JA, Stein E. Association of lipoprotein(a), insulin resistance, and reproductive hormones in a multiethnic cohort of pre- and perimenopausal women (The SWAN Study). Am J Cardiol 2003;92:533-7.

156. Sutton-Tyrrell K, Wildman RP, Matthews KA, Chae C, Lasley BL, Brockwell S, Pasternak RC, Lloyd-Jones D, Sowers MF, Torrens JI. Sexhormone-binding globulin and the free androgen index are related to cardiovascular risk factors in multiethnic premenopausal and perimenopausal women enrolled in the Study of Women Across the Nation (SWAN). Circulation 2005;111:1242-9.

157. Mantzoros CS, Georgiadis EI, Young R, Evagelopoulou C, Khoury S, Katsilambros N, Sowers JR. Relative androgenicity, blood pressure levels, and cardiovascular risk factors in young healthy women. Am J Hypertens 1995;8:606-14.

158. Sowers MR, Jannausch M, Randolph JF, McConnell D, Little R, Lasley B, Pasternak R, Sutton-Tyrrell K, Matthews KA. Androgens are associated with hemostatic and inflammatory factors among women at the mid-life. J Clin Endocrinol Metab 2005;90:6064-71.

159. Yarali H, Yildirir A, Aybar F, Kabakci G, Bukulmez O, Akgul E, Oto A. Diastolic dysfunction and increased serum homocysteine concentrations may contribute to increased cardiovascular risk in patients with polycystic ovary syndrome. Fertil Steril 2001;76:511-6.

160.Diamanti-Kandarakis E, Palioniko G, Alexandraki K, Bergiele A, Koutsouba T, Bartzis M. The prevalence of $4 \mathrm{G} 5 \mathrm{G}$ polymorphism of plasminogen activator inhibitor-1 (PAI-1) gene in polycystic ovarian syndrome and its association with plasma PAI-1 levels. Eur J Endocrinol 2004;150:793-8.

161. Rexrode KM, Manson JE, Lee IM, Ridker PM, Sluss PM, Cook NR, Buring JE. Sex hormone levels and risk of cardiovascular events in postmenopausal women. Circulation 2003;108:1688-93.

162.Haffner SM, Valdez RA, Morales PA, Hazuda HP, Stern MP. Decreased sex hormone-binding globulin predicts noninsulin-dependent diabetes mellitus in women but not in men. J Clin Endocrinol Metab 1993;77:56-60. 
163.Goodman-Gruen D, Barrett-Connor E. Sex hormone-binding globulin and glucose tolerance in postmenopausal women. The Rancho Bernardo Study. Diabetes Care 1997;20:645-9.

164. Maturana MA, Spritzer PM. Association between hyperinsulinemia and endogenous androgen levels in peri- and postmenopausal women. Metabolism 2002;51:238-43.

165. Korytkowski MT, Krug EI, Daly MA, Deriso L, Wilson JW, Winters SJ. Does androgen excess contribute to the cardiovascular risk profile in postmenopausal women with type 2 diabetes? Metabolism 2005;54:1626-31.

166. Olszanecka-Glinianowicz M, Banas M, Zahorska-Markiewicz B, Janowska J, Kocelak P, Madej P, Klimek K. Is the polycystic ovary syndrome associated with chronic inflammation per se? Eur J Obstet Gynecol Reprod Biol 2007;133:197-202.

167.Pradhan AD, Manson JE, Rifai N, Buring JE, Ridker PM. C-reactive protein, interleukin 6 , and risk of developing type 2 diabetes mellitus. JAMA 2001;286:327-34.

168. Shakeri-Manesch S, Zeyda M, Huber J, Ludvik B, Prager G, Stulnig TM. Diminished upregulation of visceral adipose heme oxygenase-1 correlates with waist-to-hip ratio and insulin resistance. Int J Obes (Lond) 2009.

169. Hotamisligil GS. Inflammatory pathways and insulin action. Int J Obes Relat Metab Disord 2003;27 Suppl 3:S53-5.

170.Huber J, Kiefer FW, Zeyda M, Ludvik B, Silberhumer GR, Prager G, Zlabinger GJ, Stulnig TM. CC chemokine and CC chemokine receptor profiles in visceral and subcutaneous adipose tissue are altered in human obesity. $\mathrm{J}$ Clin Endocrinol Metab 2008;93:3215-21.

171.Skurk T, Herder C, Kraft I, Muller-Scholze S, Hauner H, Kolb H. Production and release of macrophage migration inhibitory factor from human adipocytes. Endocrinology 2005;146:1006-11.

172.Ruan H, Zarnowski MJ, Cushman SW, Lodish HF. Standard isolation of primary adipose cells from mouse epididymal fat pads induces inflammatory mediators and down-regulates adipocyte genes. J Biol Chem 2003;278:47585-93.

173. Weisberg SP, Hunter D, Huber R, Lemieux J, Slaymaker S, Vaddi K, Charo I, Leibel RL, Ferrante AW, Jr. CCR2 modulates inflammatory and metabolic effects of high-fat feeding. J Clin Invest 2006;116:115-24.

174. Tamura Y, Sugimoto M, Murayama T, Ueda Y, Kanamori H, Ono K, Ariyasu H, Akamizu T, Kita T, Yokode M, Arai H. Inhibition of CCR2 ameliorates insulin resistance and hepatic steatosis in $\mathrm{db} / \mathrm{db}$ mice. Arterioscler Thromb Vasc Biol 2008;28:2195-201.

175.Mine S, Okada Y, Tanikawa T, Kawahara C, Tabata T, Tanaka Y. Increased expression levels of monocyte CCR2 and monocyte chemoattractant protein-1 in patients with diabetes mellitus. Biochem Biophys Res Commun 2006;344:780-5. 
176. Mathieu P, Poirier P, Pibarot P, Lemieux I, Despres JP. Visceral obesity: the link among inflammation, hypertension, and cardiovascular disease. Hypertension 2009;53:577-84.

177. Bautista LE, Vera LM, Arenas IA, Gamarra G. Independent association between inflammatory markers (C-reactive protein, interleukin-6, and TNFalpha) and essential hypertension. J Hum Hypertens 2005;19:149-54.

178. Hauner H. Secretory factors from human adipose tissue and their functional role. Proc Nutr Soc 2005;64:163-9.

179.Harman-Boehm I, Bluher M, Redel H, Sion-Vardy N, Ovadia S, Avinoach E, Shai I, Kloting N, Stumvoll M, Bashan N, Rudich A. Macrophage infiltration into omental versus subcutaneous fat across different populations: effect of regional adiposity and the comorbidities of obesity. J Clin Endocrinol Metab 2007;92:2240-7.

180.Poulain-Godefroy O, Lecoeur C, Pattou F, Fruhbeck G, Froguel P. Inflammation is associated with a decrease of lipogenic factors in omental fat in women. Am J Physiol Regul Integr Comp Physiol 2008;295:R1-7.

181.Filippatos TD, Kiortsis DN, Liberopoulos EN, Mikhailidis DP, Elisaf MS. A review of the metabolic effects of sibutramine. Curr Med Res Opin 2005;21:457-68.

182.Appolinario JC, Bacaltchuk J, Sichieri R, Claudino AM, Godoy-Matos A, Morgan C, Zanella MT, Coutinho W. A randomized, double-blind, placebo-controlled study of sibutramine in the treatment of binge-eating disorder. Arch Gen Psychiatry 2003;60:1109-16.

183.Pasquali R, Casimirri F, Vicennati V. Weight control and its beneficial effect on fertility in women with obesity and polycystic ovary syndrome. Hum Reprod 1997;12 Suppl 1:82-7.

184. Rosner W. Plasma steroid-binding proteins. Endocrinol Metab Clin North Am 1991;20:697-720.

185.Preziosi P, Barrett-Connor E, Papoz L, Roger M, Saint-Paul M, Nahoul K, Simon D. Interrelation between plasma sex hormone-binding globulin and plasma insulin in healthy adult women: the telecom study. J Clin Endocrinol Metab 1993;76:283-7.

186.Panidis D, Farmakiotis D, Rousso D, Kourtis A, Katsikis I, Krassas G. Obesity, weight loss, and the polycystic ovary syndrome: effect of treatment with diet and orlistat for 24 weeks on insulin resistance and androgen levels. Fertil Steril 2008;89:899-906.

187.Escobar-Morreale HF, Botella-Carretero JI, Alvarez-Blasco F, Sancho J, San Millan JL. The polycystic ovary syndrome associated with morbid obesity may resolve after weight loss induced by bariatric surgery. J Clin Endocrinol Metab 2005;90:6364-9. 


\section{Acta Universitatis Upsaliensis}

Digital Comprehensive Summaries of Uppsala Dissertations from the Faculty of Medicine 534

Editor: The Dean of the Faculty of Medicine

A doctoral dissertation from the Faculty of Medicine, Uppsala University, is usually a summary of a number of papers. A few copies of the complete dissertation are kept at major Swedish research libraries, while the summary alone is distributed internationally through the series Digital Comprehensive Summaries of Uppsala Dissertations from the Faculty of Medicine. (Prior to January, 2005, the series was published under the title "Comprehensive Summaries of Uppsala

Dissertations from the Faculty of Medicine".) 